\title{
Modeling and Experimental Validation of a High-Power Lithium-Ion Pouch Cell with LCO/NCA Blend Cathode
}

\author{
Serena Carelli, $\odot^{\mathrm{Z}}$ Michael Quarti, Mehmet C. Yagci, and Wolfgang G. Bessler* \\ Institute of Energy Systems Technology (INES), Offenburg University of Applied Sciences, 77652 Offenburg, Germany
}

\begin{abstract}
This article presents the development, parameterization, and experimental validation of a pseudo-three-dimensional (P3D) multiphysics model of a $350 \mathrm{mAh}$ high-power lithium-ion pouch cell with graphite anode and lithium cobalt oxide/lithium nickel cobalt aluminum oxide (LCO/NCA) blend cathode. The model describes transport processes on three different scales: Heat transport on the macroscopic scale (cell), mass and charge transport on the mesoscopic scale (electrode pair), and mass transport on the microscopic scale (active material particles). A generalized description of electrochemistry in blend electrodes is developed, using the open-source software Cantera for calculating species source terms. Very good agreement of model predictions with galvanostatic charge/discharge measurements, electrochemical impedance spectroscopy, and surface temperature measurements is observed over a wide range of operating conditions $\left(0.05 \mathrm{C}\right.$ to $10 \mathrm{C}$ charge and discharge, $5^{\circ} \mathrm{C}$ to $35^{\circ} \mathrm{C}$ ). The behavior of internal states (concentrations, potentials, temperatures) is discussed. The blend materials show a complex behavior with both intra-particle and inter-particle non-equilibria during cycling.

(C) The Author(s) 2019. Published by ECS. This is an open access article distributed under the terms of the Creative Commons Attribution 4.0 License (CC BY, http://creativecommons.org/licenses/by/4.0/), which permits unrestricted reuse of the work in any medium, provided the original work is properly cited. [DOI: 10.1149/2.0301913jes]
\end{abstract}

Manuscript submitted May 14, 2019; revised manuscript received August 2, 2019. Published September 3, 2019.

The macroscopically observable behavior of lithium-ion cells in terms of current, voltage and temperature dynamics is governed by a strong coupling of electrochemistry and transport on multiple scales inside the cell. In order to unravel the impact of the multi-scale and multi-physical internal processes on macroscopic cell behavior, modeling and simulation techniques have proven highly useful. ${ }^{2}$ For the coupling of scales and physics, pseudo-2D (P2D) models are being used extensively in the lithium-ion cell modeling community, covering mass transport at the particle scale (referred to as microscale in the following) and mass and charge transport at the electrode-pair scale (mesoscale). ${ }^{5,6}$ These models have been extended by heat transport on the cell scale (macroscale), resulting in $\mathrm{P} 2 \mathrm{D}+1 \mathrm{D},{ }^{8,9}$ pseudo3D (P3D) $)^{1,10,11}$ or P2D+3D ${ }^{12}$ models, also referred to as multi-scale multi-domain (MSMD) models. ${ }^{13}$

A blend electrode is an electrode with more than one single active material (AM). Blending of AM is commonly used to tailor the overall electrode performance toward specific requirements. ${ }^{14,15}$ Blends can be applied both in the positive electrode (e.g., LMO/NMC) ${ }^{16}$ and the negative electrode (e.g., graphite/silicon). ${ }^{17}$ The modeling of lithium-ion batteries with blend electrodes is more complex than those of single-material electrodes due to both, the requirement of implementing competing charge-transfer reactions, and the increasing effort for parameter identification. Few models that include blend electrodes were demonstrated before. Albertus ${ }^{18}$ modified a previouslydeveloped lithium-ion cell model to treat blend electrodes built with several compositions of LMO/NCA as AM. In Jung ${ }^{19}$ a physics-based dynamic model of lithium-ion cells with LMO/NMC blend cathodes is presented: the model is able to run simulations under various operating conditions and is showing a good agreement with the experimental data. Mao et al. ${ }^{20}$ developed and adapted a P2D electrochemical model to describe the performance of an LMO/NMC blend electrode from a commercial lithium-ion battery: the model is able to simulate nonuniform size distribution and chemical composition. In a paper from Rodriguez and Plett, ${ }^{21}$ a physics-based model inspired by the work from Albertus ${ }^{18}$ is developed with the purpose of modeling electrodes composed of multiple AM. Appiah et al. ${ }^{22}$ described a multi-scale mathematical model by employing a P2D approach on coin cells with LMO/NMC blend cathodes along with capacity-fade simulation and performance analysis.

The explanatory power of simulations is only significant if the model is thoroughly validated experimentally. This is true, in particular, for models that show both, transport complexity (P3D transport)

*Electrochemical Society Member.

${ }^{\mathrm{z} E-m a i l: ~ s e r e n a . c a r e l l i @ h s-o f f e n b u r g . d e ~}$ and chemical complexity (blend electrode), as studied here. Modeling, parameterization and experimental validation are therefore closely linked, requiring dedicated experiments. ${ }^{23}$

This article presents the development, parameterization, and experimental validation of a P3D model of a commercial $350 \mathrm{mAh}$ highpower lithium-ion pouch cell with graphite anode and lithium cobalt oxide/lithium nickel cobalt aluminum oxide (LCO/NCA) blend cathode. This work introduces the following original features: (i) Combined modeling and experimental study that demonstrate model validity over a wide range of C-rates and temperatures, both in the time and frequency domains; (ii) a generalized description of electrochemistry in blend electrodes, using the open-source software Cantera ${ }^{24}$ for calculating species source terms; (iii) systematic parameterization of electrochemistry and P3D transport using combined literature and original experimental data. The behavior of internal states during a discharge/charge cycle is shown and discussed.

\section{Methodology}

Investigated cell.-This study is devoted to a commercial $350 \mathrm{mAh}$ high-power lithium-ion pouch cell by the manufacturer Kokam (type SLPB283452H). The cell chemistry was identified before as graphite at the anode and NCA/LCO blend at the cathode. ${ }^{3}$

P3D model with detailed chemistry.-We use a P3D model that was developed and parameterized before for representing a lithium iron phosphate (LFP)/graphite high-power cylindrical cell. ${ }^{1}$ It was applied to both aging ${ }^{25}$ and high-temperature behavior, ${ }^{26}$ demonstrating the versatility of P3D models with detailed chemistry. The transport scales are shown schematically in Figure 1 and combine heat transport through the cell thickness and holder plates (in this paper referred to as macroscale or $x$ scale), mass and charge transport inside the liquid electrolyte (mesoscale, $y$ scale), and diffusive mass transport in the AM particles (microscale, $z$ scale), each solved in 1D and coupled via appropriate boundary conditions and upscaling relationships. The chemistry is described within a generalized framework allowing an arbitrary number and type of reactions at each of the involved interfaces. Thermodynamics and kinetics are evaluated with the opensource software Cantera, ${ }^{24}$ allowing a consistent definition and simple exchange of parameters. The model includes a multi-phase description of primary and secondary phases, allowing, for example, to track gas formation inside the cell. The reader is referred to Refs. 1 for a detailed model description including all model equations and symbol definitions. 


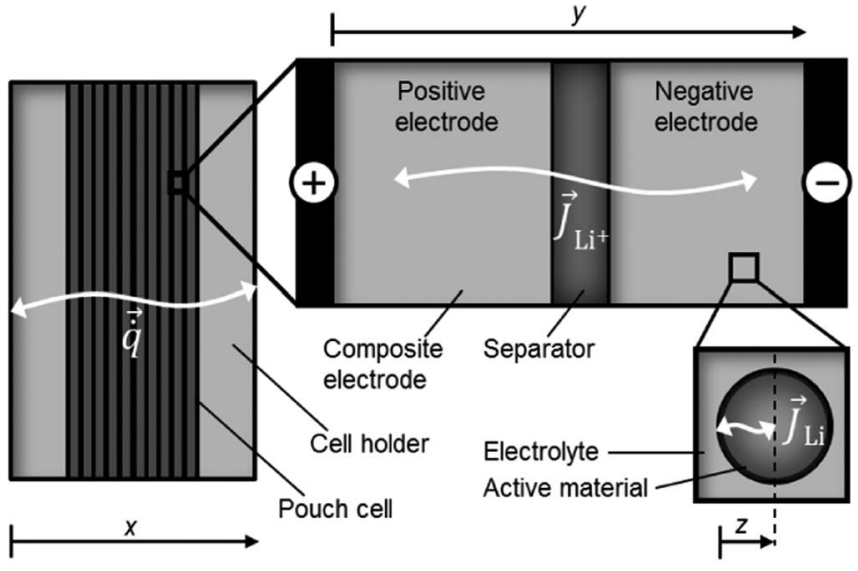

Figure 1. Schematic representation of 1D+1D+1D (pseudo-3D, P3D) modeling domain ${ }^{1}$ with macroscale $(x)$, mesoscale $(y)$ and microscale $(z)$.

In the present work, we extend the model by the capability of describing blend electrodes, and completely re-parameterize it in order to represent the target cell.

Blend electrode model. - We generalize the base mode ${ }^{1,25}$ in order to allow to include an arbitrary number of different $\mathrm{AM}$ with individual geometric, transport and chemical properties in each electrode. We assume:

- Each electrode (anode, cathode) can have an arbitrary number of different $\mathrm{AM} N_{\mathrm{AM}}$ that we describe by a continuous index $i$. In the most simple model, $N_{\mathrm{AM}}=2$ (one at the anode and one at the cathode). More AM can be used for representing blend electrodes or for representing particle size distributions (same material, different radius). In the present work, $i=\{\mathrm{NCA}, \mathrm{LCO}$, graphite $\}$ and $N_{\mathrm{AM}}=3$.

- Each AM consists of two species, lithium Li[AM, $i]$ and vacancies $\mathrm{V}[\mathrm{AM}, i]$

- Each AM consists of spherical particles.

Each AM is characterized by the density $\rho_{\mathrm{AM}, i}$, the particle radius $r_{\mathrm{AM}, i}$, the initial volume fraction $\varepsilon_{\mathrm{AM}, i}$ (note the volume fraction changes during cycling due to expansion upon intercalation), its location (anode or cathode), a solid-state diffusion coefficient of lithium $D_{\mathrm{Li}[\mathrm{AM}, i]}\left(X_{\mathrm{Li}[\mathrm{AM}, i]}\right)$ which depends on the lithium mole fraction $X_{\mathrm{Li}[\mathrm{AM}, i]}$, as well as the stoichiometry range the material is balanced to inside the cell, represented by the parameters $X_{\mathrm{Li}[\mathrm{AM}, i]}^{\mathrm{SOC}=0}$ and $X_{\mathrm{Li}[\mathrm{AM}, i]}^{\mathrm{SOC}=1}$. Furthermore, for the simulation, the number and size of finite-volume discretization compartments is specified.

Mass conservation within the spherical particle of each AM is described by Fick's law in spherical coordinates using the intercalated lithium density $\rho_{\mathrm{Li}[\mathrm{AM}, i]}$ as field variable,

$$
\frac{\partial \rho_{\mathrm{Li}[\mathrm{AM}, i]}}{\partial t}=\frac{1}{r^{2}} \frac{\partial}{\partial r}\left(r^{2} D_{\mathrm{Li}[\mathrm{AM}, i]}\left(X_{\mathrm{Li}[\mathrm{AM}, i]}\right) \frac{\partial \rho_{\mathrm{Li}[\mathrm{AM}, i]}}{\partial r}\right) .
$$

The boundary flux at the particle/electrolyte interface is given as ${ }^{25}$

$$
\begin{aligned}
\left.j_{\mathrm{Li}[\mathrm{AM}, i]}\right|_{r=r_{\mathrm{AM}, i}=} & \frac{1}{A_{\mathrm{AM}, i}^{V}} \cdot \frac{1}{\varepsilon_{\mathrm{AM}, i}}\left(\left(1-\frac{\rho_{\mathrm{Li}[\mathrm{AM}, i]}}{\rho_{\mathrm{AM}, i}}\right) \dot{s}_{\mathrm{Li}[\mathrm{AM}, i]}^{V} \cdot M_{\mathrm{Li}[\mathrm{AM}, i]}\right. \\
& \left.-\frac{\rho_{\mathrm{Li}[\mathrm{AM}, i]}}{\rho_{\mathrm{AM}, i}} \dot{s}_{\mathrm{V}[\mathrm{AM}, i]}^{V} \cdot M_{\mathrm{V}[\mathrm{AM}, i]}\right)
\end{aligned}
$$

where, the AM specific surface area $A_{\mathrm{AM}, i}^{V}$ is given as

$$
A_{\mathrm{AM}, i}^{V}=\frac{3}{r_{\mathrm{AM}, i}},
$$

and $\dot{s}_{\mathrm{Li}[\mathrm{AM}, i]}^{V}$ and $\dot{s}_{\mathrm{V}[\mathrm{AM}, i]}^{V}$ are the volumetric source terms for lithium and vacancies, respectively. The generalized flux expression 2 allows to distinguish between intercalation reactions and AM loss reactions in case of more complex kinetic models. ${ }^{25}$ At the particle center,

$$
\left.j_{\mathrm{Li}[\mathrm{AM}, i]}\right|_{r=0}=0 \text {. }
$$

Note we define the $z$ scale inverse to the radial scale (cf. Figure 1). The degree of lithiation can be either described by the lithium density $\rho_{\mathrm{Li}[\mathrm{AM}, i]}$ or the lithium mole fraction $X_{\mathrm{Li}[\mathrm{AM}, i]}$, which can be interconverted according to

$$
X_{\mathrm{Li}[\mathrm{AM}, i]}=\frac{\rho_{\mathrm{Li}[\mathrm{AM}, i]}}{\rho_{\mathrm{Li}[\mathrm{AM}, i]}+\frac{M_{\mathrm{Li}[\mathrm{AM}, i]}}{M_{\mathrm{V}[\mathrm{AM}, i]}}\left(\rho_{\mathrm{AM}, i}-\rho_{\mathrm{Li}[\mathrm{AM}, i]}\right)} .
$$

We obtain the species source terms $\dot{s}_{\mathrm{Li}[\mathrm{AM}, i]}^{V}$ and $\dot{s}_{\mathrm{V}[\mathrm{AM}, i]}^{V}$ from Cantera, ${ }^{24}$ which is our dedicated tool for electrochemical thermodynamics and kinetics. Specifically, the local thermodynamic state in terms of temperature, pressure, electrode potential, electrolyte potential, and lithium mole fraction at the particle surface is passed to Cantera, which returns species net production rates. Cantera's internal calculation is based on a library of thermodynamic and kinetic parameters of all involved phases, species, interfaces, and reactions, the parameterization of which will be described below. A more detailed insight into the models implemented in Cantera is given by Mayur et al. ${ }^{27}$ and therefore not repeated here. For the blend electrode, we assume that the local temperature, pressure, electrode potential, electrolyte potential, as well as electrolyte composition are identical for all AM in the blend. Therefore, the blend components are thermodynamically and kinetically coupled.

Macroscopically we are often interested in the state of charge (SOC). For each individual AM, the SOC is given by

$$
\mathrm{SOC}_{i}=\frac{\bar{X}_{\mathrm{Li}[\mathrm{AM}, i]}-X_{\mathrm{Li}[\mathrm{AM}, i]}^{\mathrm{SOC}=0}}{X_{\mathrm{Li}[\mathrm{AM}, i]}^{\mathrm{SOC}, 1}-X_{\mathrm{Li}[\mathrm{AM}, i]}^{\mathrm{SOC}, i]},}
$$

where, the average lithium mole fraction follows from integration of the density over the particle volume,

$$
\bar{\rho}_{\mathrm{Li}[\mathrm{AM}, i]}=\frac{3}{r_{\mathrm{AM}, i}^{3}} \int_{0}^{r_{\mathrm{AM}, i}} \rho_{\mathrm{Li}[\mathrm{AM}, i]}(r) r^{2} \mathrm{~d} r,
$$

and using Eq. 5. The overall SOC of an electrode results from a weighted average of the SOCs of the individual AM,

$$
\mathrm{SOC}_{\text {elde }}=\frac{\sum_{i=1}^{N_{\mathrm{AM}, \text { elde }}}\left(\mathrm{SOC}_{i} \cdot C_{\mathrm{AM}, i}^{V}\right)}{\sum_{i=1}^{N_{\mathrm{AM}, \text { elde }}}\left(C_{\mathrm{AM}, i}^{V}\right)} .
$$

The individual overall capacity $C_{\mathrm{AM}, i}^{V}$ of the $\mathrm{AM} i$ in the electrode (in $\mathrm{C} / \mathrm{m}^{3}$ ) is given as

$$
C_{\mathrm{AM}, i}^{V}=z_{i} F \varepsilon_{\mathrm{AM}, i} \frac{\rho_{\mathrm{AM}, i}}{M_{\mathrm{Li}[\mathrm{AM}, i]}}\left|X_{\mathrm{Li}[\mathrm{AM}, i]}^{\mathrm{SOC}=1}-X_{\mathrm{Li}[\mathrm{AM}, i]}^{\mathrm{SOC}=0}\right| .
$$

Simulation methodology. - The P3D model with blend electrode functionality presented above is implemented in the in-house multiphysics software package DENIS (Detailed Electrochemistry and Numerical Impedance Simulation $)^{1}$ and numerically solved using the implicit time-adaptive solver LIMEX. ${ }^{28,29}$ The spatial derivatives were discretized in a finite-volume scheme, using 20, 19 and 11 nonequidistant control volumes on the $x, y$ and $z$ scales, respectively. The cell is represented by one single electrode pair.

The chemistry is based on the use of the open-source chemical kinetics code Cantera, ${ }^{24}$ enabling the thermodynamically consistent description of the blend electrode. Cantera is coupled to the DENIS transport model via the chemistry source terms. ${ }^{27}$ For the three AM (NCA, LCO, graphite) we use Cantera's BinarySolutionTabulatedThermo class. The electrolyte phase is described through the IdealSolidSolution class, with the standard concentration set to a unity value.

MATLAB (version 2019a) is the chosen interface for controlling all DENIS simulations, as well as for data evaluation and visualization. Electrochemical impedance simulations were performed using a current step/voltage relaxation protocol and subsequent Fourier transform. ${ }^{30}$ 
Table I. Thermodynamic properties of all species included in the model.

\begin{tabular}{llll} 
Species & Molar enthalpy $h_{i} / \mathrm{kJ} \cdot \mathrm{mol}^{-1}$ & Molar entropy $s_{i} / \mathrm{J} \cdot \mathrm{mol}^{-1} \cdot \mathrm{K}^{-1}$ & Reference \\
\hline $\mathrm{Li}[\mathrm{LCO}]$ & See Figure 2a & See Figure 2a & $3,27,31,32$ \\
$\mathrm{~V}[\mathrm{LCO}]$ & 0 & 0 & Reference value \\
$\mathrm{Li}[\mathrm{NCA}]$ & See Figure 2b & See Figure 2b & $3,27,33,34$ \\
$\mathrm{~V}[\mathrm{NCA}]$ & 0 & 0 & Reference value \\
$\mathrm{Li}\left[\mathrm{C}_{6}\right]$ & See Figure 2c & See Figure 2c & $3,27,35,36$ \\
$\mathrm{~V}\left[\mathrm{C}_{6}\right]$ & 0 & 0 & Reference value \\
$\mathrm{C}_{3} \mathrm{H}_{4} \mathrm{O}_{3}[\mathrm{elyt}]$ & $-578^{*}$ & $175^{*}$ & 66 \\
$\mathrm{C}_{4} \mathrm{H}_{8} \mathrm{O}_{3}[\mathrm{elyt}]$ & 0 & 0 & Dummy value (not chemically active) \\
$\mathrm{Li}^{+}[$elyt] & 0 & 0 & Assumed \\
$\mathrm{PF}_{6}^{-}[\mathrm{elyt}]$ & 0 & 0 & Dummy value (not chemically active)
\end{tabular}

*Values are assumed $T$-dependent, ${ }^{66}$ here given at $298 \mathrm{~K}$.

Experimental methodology.-Cell-level experiments were carried out in order to obtain model parameters and validation data. Electrical cycling tests (BaSyTec GSM) were carried out with two individual cells at different ambient temperatures $\left(5^{\circ} \mathrm{C}, 20^{\circ} \mathrm{C}, 35^{\circ} \mathrm{C}\right.$, CTS T$40 / 200 \mathrm{Li}$ climate chamber) and at different C-rates between $\mathrm{C} / 20$ and $10 \mathrm{C}$ with $\mathrm{CCCV}$ protocol $(3.0 \mathrm{~V}$ and $4.2 \mathrm{~V}$ cutoff voltages, $\mathrm{C} / 20 \mathrm{CV}$ cutoff current, $30 \mathrm{~min}$ rest). Electrochemical impedance spectra were recorded (Gamry Reference 3000) at different SOC (20\%, 50\%, 80\% only at $20^{\circ} \mathrm{C}$ ) and the same ambient temperatures. For well-defined mechanical boundary conditions, the investigated cell was placed between two aluminum plates under mechanical load $\left(50000 \mathrm{~N} / \mathrm{m}^{2}\right)$. Temperature was measured on the surface of the aluminum plate. One individual cell was opened in order to investigate internal geometry and morphology; the methodology and resulting data are given in detail by Mayur et al. ${ }^{3}$

\section{Model Parameterization}

We introduce and present a systematic approach toward model parameterization.

Cell at thermodynamic equilibrium.-The base parameters needed for the lithium-ion battery model are those that are associated with the thermodynamic equilibrium, that is, that describe the open-circuit voltage $V^{0}$ as function of charge throughput $Q$. Parameters related to nonequilibrium effects such as transport on multiple scales and finite reaction kinetics can only be identified reliably if the equilibrium behavior is modeled correctly.

We start by collecting molar thermodynamic properties (molar enthalpies $h_{\mathrm{Li}[\mathrm{AM}, i]}^{0}$ and molar entropies $s_{\mathrm{Li}[\mathrm{AM}, i]}^{0}$ ) of intercalated lithium in the AM NCA, LCO and graphite. They are calculated from literature experiments of half-cell potential vs. lithium metal $E_{\mathrm{AM}, i}^{\mathrm{eq}}$ and their temperature dependence $E_{\mathrm{AM}, i}^{\mathrm{eq}} / \mathrm{d} T$, including a correction for the entropy of the lithium metal counter electrode. ${ }^{27}$ Data were selected and processed for $\mathrm{LCO},{ }^{31,32} \mathrm{NCA}^{33,34}$ and graphite. ${ }^{35,36}$ The resulting molar thermodynamic data are shown in Figure 2. We furthermore collected molar thermodynamic data for all other species present in the model. They are summarized in Table I. They form the thermochemical basis of the model.

Apart from the chemical thermodynamics, the $V^{0}(Q)$ behavior depends on the available electrode capacity and electrode balancing, which are governed by electrode volume, volume fraction of AM, density of AM, and the stoichiometry range the AM are cycled in. Here we apply the methodology developed by Mayur et al. ${ }^{3}$ for self-consistent parameter identification as follows. An experimental charge/discharge cycle at low C-rate (here: $\mathrm{C} / 20$ ) is recorded. The cell is opened and the thicknesses of the electrodes and total electrode area are measured. Modeled $V^{0}(Q)$ curves are compared to the experimental cycle data, and volume fractions and stoichiometry ranges of all AM are identified through mathematical optimization. The resulting parame-
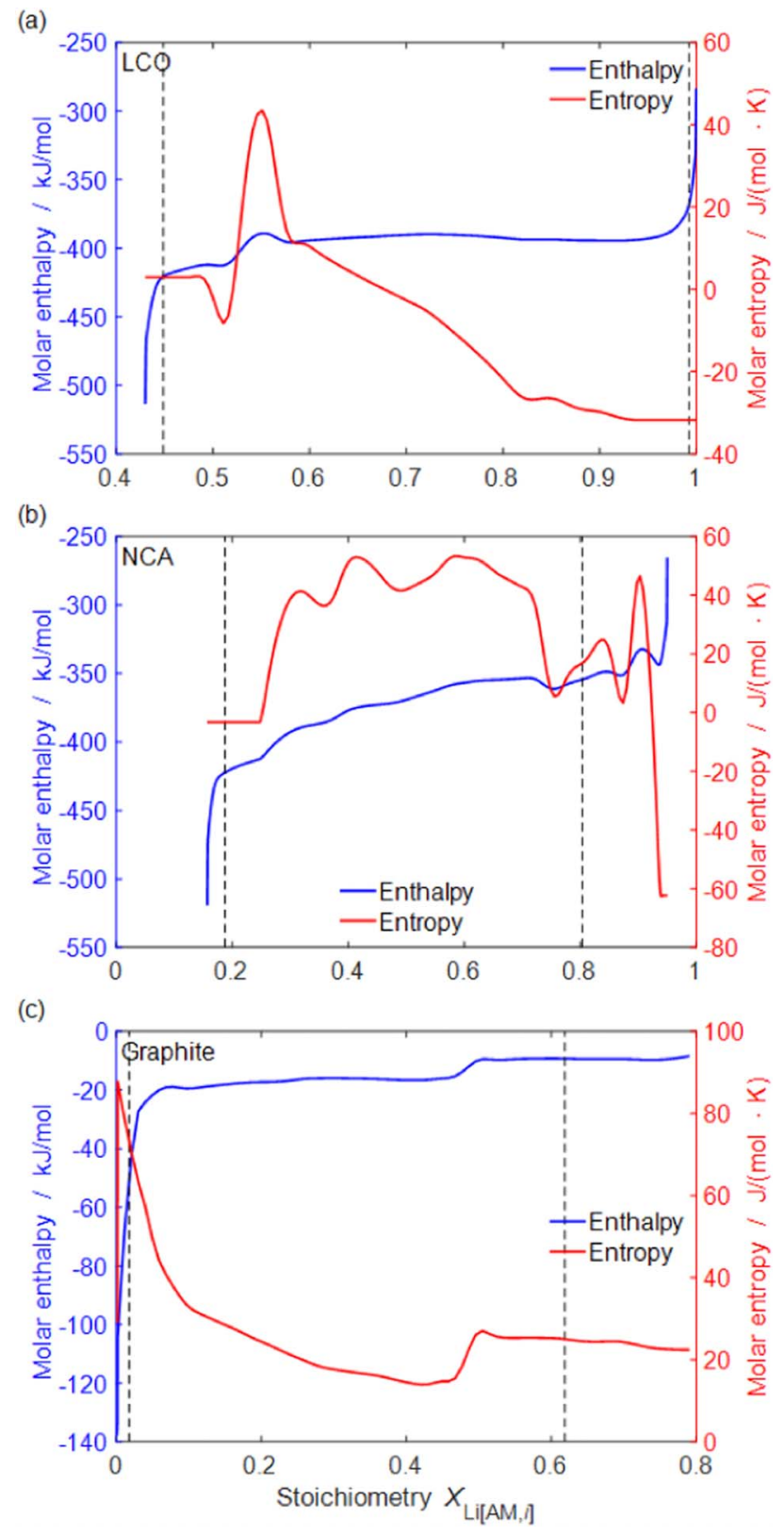

Figure 2. Molar enthalpies and entropies of intercalated lithium within the three AM (a) LCO, (b) NCA and (c) graphite. The vertical dashed lines indicate the stoichiometry ranges for every AM, as obtained through optimization. See text and Ref. 3 for details. 
Table II. Properties of all bulk phases included in the model.

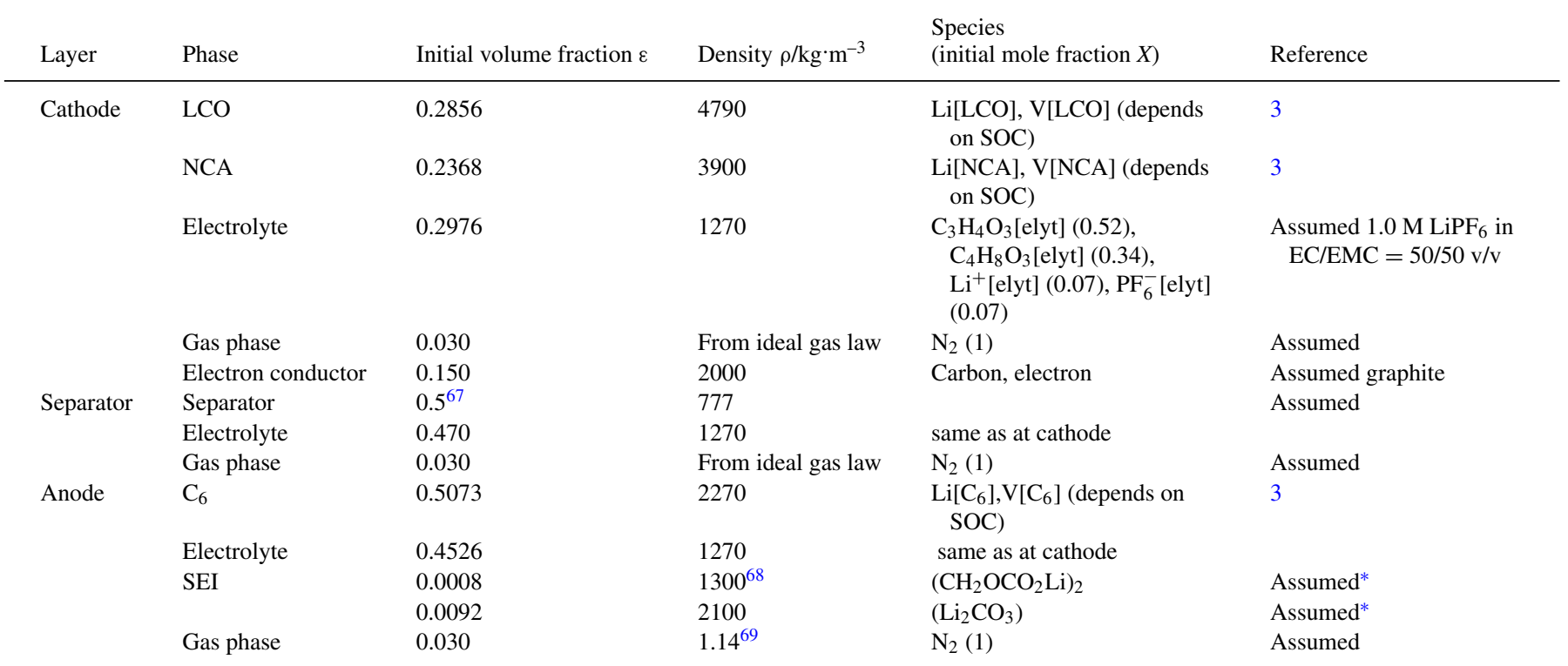

${ }^{*}$ SEI species included as placeholder for future investigations.

ters are included in Table II and in the following Tables. Furthermore, Table II defines all phases and species assumed in both electrodes and separator.

This concludes the identification of parameters required for describing the equilibrium case. We next determine transport parameters on macro-, meso- and microscale and finally the reaction kinetic parameters.

Macroscale: thermal parameters.-All geometrical and transport parameters of the macroscale (cell scale) are summarized in Table III. For the heat transport the main parameters are thermal conductivity and heat capacity of the used materials. The heat capacity for a similar battery with LCO/NCA blend cathode and graphite anode was determined by Loges et al. ${ }^{37}$ Values between $0.9 \mathrm{~J} /(\mathrm{g} \cdot \mathrm{K})$ at $0^{\circ} \mathrm{C}$ up to $1.05 \mathrm{~J} /(\mathrm{g} \cdot \mathrm{K})$ at $50^{\circ} \mathrm{C}$ have been measured, therefore we decided to use $0.95 \mathrm{~J} /(\mathrm{g} \cdot \mathrm{K})$ as temperature-independent value. To our knowledge no values for the heat conductivity of cells with blend cathode (LCO/NCA) and graphite anode have been published, therefore we assumed $0.9 \mathrm{~W} /(\mathrm{m} \cdot \mathrm{K})$ as through-plane heat conductivity as typical value for a lithium-cell. ${ }^{38}$

In order to allow for a direct comparison to experiments, it is also required to simulate the aluminum holder plates as thermal surround- ings of the cell. The thermal parameters for aluminum were taken from literature. The heat transfer coefficient between aluminum plates and surrounding was obtained by fitting simulated temperature decay to experimental data. It should be noted that the aluminum plates had larger lateral dimensions $(5.8 \times 5.0 \mathrm{~cm})$ than the cell $(5.2 \times 3.35 \mathrm{~cm})$. This $3 \mathrm{D}$ effect cannot be described by the present $1 \mathrm{D}$ model. In order to compensate for 3D effects, the plate thicknesses and the heat transfer coefficient were adjusted, leading to larger values for these parameters used in the 1D model.

Mesoscale: electrolyte transport model and parameters.-All geometrical and transport parameters of the mesoscale (electrode pair) are summarized in Table IV. According to the cell data sheet, the electrolyte is composed of $\mathrm{EC}, \mathrm{EMC}$, and $\mathrm{LiPF}_{6}$; the exact composition is unknown. Table $\mathrm{V}$ gives an overview of available literature data of conductivity as function of lithium ion concentration and/or temperature for this electrolyte system. We use an electrolyte transport model based on dilute solution theory, ${ }^{1}$ but use concentration-dependent diffusivities (accounting for the interaction between the ions in the concentrated solution). The main reason not to apply the commonly-used concentrated solution theory ${ }^{6,8}$ is the higher complexity of parameterization, which is not feasible as the exact nature of the present electrolyte is unknown.

\section{Table III. Macroscale: Geometric and thermal parameters.}

\begin{tabular}{|c|c|c|c|}
\hline Parameter & Domain & Value & Reference \\
\hline Thickness & Left aluminum plate & $0.0083 \mathrm{~mm}$ & Measured* \\
\hline Thickness & Cell & $3 \mathrm{~mm}$ & Measured \\
\hline Thickness & Right aluminum plate & $0.019 \mathrm{~mm}$ & Measured* \\
\hline Thermal conductivity $\lambda$ & Left/right aluminum plate & $237 \mathrm{~W} \cdot \mathrm{m}^{-1} \cdot \mathrm{K}^{-1}$ & 70 \\
\hline Thermal conductivity $\lambda$ & Cell & $0.9 \mathrm{~W} \cdot \mathrm{m}^{-1} \cdot \mathrm{K}^{-1}$ & 38 \\
\hline Heat capacity $\rho c_{\mathrm{P}}$ & Left/right aluminum plate & $0.897 \mathrm{~J} \cdot \mathrm{g}^{-1} \cdot \mathrm{K}^{-1}$ & 70 \\
\hline Emissivity $\epsilon$ & Aluminum plate surface & 0.15 & 71 \\
\hline
\end{tabular}

*Values include correction for 1D computational domain. 
Table IV. Mesoscale: Geometry and transport parameters of the electrode-pair scale.

\begin{tabular}{|c|c|c|}
\hline Parameter & Value & Reference \\
\hline Thickness of cathode & $32.9 \mu \mathrm{m}$ & Measured $^{3}$ \\
\hline Thickness of separator & $15.7 \mu \mathrm{m}$ & Measured $^{3}$ \\
\hline Thickness of anode & $49.1 \mu \mathrm{m}$ & Measured $^{3}$ \\
\hline Tortuosity of cathode $\tau$ & 1.35 & Calculated from Bruggeman relationship \\
\hline Tortuosity of separator $\tau$ & 1.21 & Calculated from Bruggeman relationship \\
\hline Tortuosity of anode $\tau$ & 1.22 & Calculated from Bruggeman relationship \\
\hline Diffusion coefficients $D_{\mathrm{Li}^{+}}, D_{\mathrm{PF}_{6}^{-}}$ & See Eqs. 13 and 14 & See Section Mesoscale: Electrolyte transport model and parameters \\
\hline Specific surface area LCO/electrolyte $A^{\mathrm{V}}$ & $6.67 \cdot 10^{5} \mathrm{~m}^{2} / \mathrm{m}^{3}$ & $3 \varepsilon_{\mathrm{AM}} / r_{A M}, r_{\mathrm{AM}}$ from Table $\mathrm{VI}^{1}$ \\
\hline Specific surface area NCA/electrolyte $A^{\mathrm{V}}$ & $4.28 \cdot 10^{6} \mathrm{~m}^{2} / \mathrm{m}^{3}$ & $3 \varepsilon_{\mathrm{AM}} / r_{A M}, r_{\mathrm{AM}}$ from Table $\mathrm{VI}^{1}$ \\
\hline Specific surface area graphite/electrolyte $A^{\mathrm{V}}$ & $2.79 \cdot 10^{5} \mathrm{~m}^{2} / \mathrm{m}^{3}$ & $3 \varepsilon_{\mathrm{AM}} / r_{A M}, r_{\mathrm{AM}}$ from Table $\mathrm{VI}^{1}$ \\
\hline Anode double layer capacitance $C_{\mathrm{DL}}^{\mathrm{V}}$ & $1.5 \cdot 10^{4} \mathrm{~F} \cdot \mathrm{m}^{-3}$ & Fitted to EIS data \\
\hline Cathode double layer capacitance $C_{\mathrm{DL}}^{\mathrm{V}}$ & $2.8 \cdot 10^{5} \mathrm{~F} \cdot \mathrm{m}^{-3}$ & Fitted to EIS data \\
\hline Ohmic resistance of current collection system $R_{\mathrm{cc}}^{0}$ & $3.648 \cdot 10^{-1} \mathrm{~m} \Omega \cdot \mathrm{m}^{2}$ & Fitted to EIS data \\
\hline Slope $\alpha_{\mathrm{cc}}($ ref. $T=293 \mathrm{~K})$ & -0.009 & Fitted to EIS data \\
\hline Electrical conductivity of the SEI layer $\sigma_{\text {SEI }}$ & $1.0 \cdot 10^{-5} \mathrm{~S} / \mathrm{m}$ & Assumed $^{52}$ \\
\hline Graphite stoichiometry range $X_{\mathrm{Li}\left[\mathrm{C}_{6}\right]}(0 \ldots 100 \%$ SOC $)$ & $0.0180 \ldots 0.6186$ & Optimization $^{3}$ \\
\hline LCO stoichiometry range $X_{\mathrm{Li}[\mathrm{LCO}]}(0 \ldots 100 \%$ SOC $)$ & $0.9922 \ldots 0.4487$ & Optimization $^{3}$ \\
\hline NCA stoichiometry range $X_{\mathrm{Li}[\mathrm{NCA}]}(0 \ldots 100 \%$ SOC $)$ & $0.8033 \ldots 0.1876$ & Optimization $^{3}$ \\
\hline
\end{tabular}

The input parameters to the model are the diffusion coefficients of $\mathrm{Li}^{+}$and $\mathrm{PF}_{6}^{-}$including their concentration and temperature dependencies. We determine these from literature measurements of the ionic conductivity $\sigma$ as function of concentration and temperature, and the transference number $t^{+}$. The definition of the transference number, ${ }^{39,40}$

$$
t^{+}=\frac{D_{\mathrm{Li}^{+}}}{\left(D_{\mathrm{Li}^{+}}+D_{\mathrm{PF}_{6}^{-}}\right)},
$$

and the Nernst-Einstein equation ${ }^{41}$ in the limit of infinite dilution (noninteracting ions),

$$
\sigma=\frac{z^{2} F^{2}}{R T} \cdot c_{\mathrm{LiPF}_{6}} \cdot\left(D_{\mathrm{Li}^{+}}+D_{\mathrm{PF}_{6}^{-}}\right),
$$

provide the necessary relationships. We assume a simple exponential dependence of the diffusion coefficients on ion concentration,

$$
D_{\mathrm{Li}^{+}}=a_{1} \exp \left(-a_{2} c_{\mathrm{Li}^{+}}\right) \text {and } D_{\mathrm{PF}_{6}^{-}}=a_{3} \exp \left(-a_{2} c_{\mathrm{PF}_{6}^{-}}\right) \text {. }
$$

We further assume an Arrhenius-type dependence on temperature and take an activation energy of $E_{\text {act }}=17.20 \mathrm{~kJ} / \mathrm{mol}$ from Zhang et al. ${ }^{7}$ in the range of $-20 /+62{ }^{\circ} \mathrm{C}$ (cf. Table V), which is similar to the value found by Ecker et al. ${ }^{35}$ of about $17.12 \mathrm{~kJ} / \mathrm{mol}$. Further assuming a (concentration-independent) value for $t^{+}=0.30,{ }^{4}$ Eqs. 10 and 11 were used to fit the parameters $a_{1}, a_{2}$ and $a_{3}$ in Eq. 12 to the concentration dependence of conductivity measured by Nyman et al. ${ }^{4}$ at $298 \mathrm{~K}$. The resulting expressions are,

$$
\begin{aligned}
D_{\mathrm{Li}^{+}}= & 2.06 \cdot 10^{-10} \mathrm{~m}^{2} \mathrm{~s}^{-1} \cdot \exp \left(-\frac{c_{\mathrm{Li}^{+}}}{1000 \mathrm{~mol} \mathrm{~m}^{-3}}\right) \\
& \cdot \exp \left(-\frac{17.20 \mathrm{~kJ} \mathrm{~mol}^{-1}}{R}\left(\frac{1}{T}-\frac{1}{298 \mathrm{~K}}\right)\right),
\end{aligned}
$$

$$
\begin{aligned}
D_{\mathrm{PF}_{6}^{-}}= & 4.81 \cdot 10^{-10} \mathrm{~m}^{2} \mathrm{~s}^{-1} \cdot \exp \left(-\frac{c_{\mathrm{PF}_{6}^{-}}}{1000 \mathrm{~mol} \mathrm{~m}^{-3}}\right) \\
& \cdot \exp \left(-\frac{17.20 \mathrm{~kJ} \mathrm{~mol}^{-1}}{R}\left(\frac{1}{T}-\frac{1}{298 \mathrm{~K}}\right)\right) .
\end{aligned}
$$

The results of this model are shown in Figure 3. Figure 3 a shows modeled and experimental electrolyte conductivity as function of concentration at $298 \mathrm{~K}$. The model is correct for concentrations $<1.5 \mathrm{~mol} / \mathrm{l}$ and deviates increasingly from experiments for higher concentrations. This is due to the fact that the underlying Equation 11 assumes dilute solution. Figure $3 \mathrm{~b}$ shows the temperature dependence of conductivity at $1 \mathrm{~mol} / \mathrm{l}$. The model is able to correctly describe the temperature dependence over a wide range between 253 and $335 \mathrm{~K}$. Note that the diffusion coefficients derived such represent bulk electrolyte properties. In the porous electrodes and separator, they are corrected for porosity $\varepsilon_{\text {elyt }}$ and geometric tortuosity $\tau_{\text {elyt }}$ according to

$$
D^{\text {eff }}=\frac{\varepsilon_{\text {elyt }}}{\tau_{\text {elyt }}^{2}} D .
$$

Connected to a proper parametrization of the electrolyte is the choice of a correct parameterization for the ohmic resistance of the current collection system, which in the present model is represented by a global resistance $R_{\mathrm{cc}}$. We assume an empirical temperature dependence according to

$$
R_{\mathrm{cc}}(T)=R_{\mathrm{cc}}^{0} \cdot\left[1.0+\alpha_{\mathrm{cc}} \cdot(T-293)\right],
$$

where the temperature dependence is described by using a slope $\alpha_{c c}$ with a reference temperature of $293 \mathrm{~K}$. The parameters $R_{\mathrm{cc}}^{0}$ and $\alpha_{\mathrm{cc}}$ were obtained by comparing simulated and experimental ohmic part of the impedance $R_{\mathrm{Ohm}}$ (i.e., $Z^{\prime}$ at a high frequency for which $Z^{\prime \prime}=0$ ). This value is related to both electrolyte resistance in the separator,

Table V. Literature conductivity data for EC/EMC/LiPF 6 electrolytes at $1 \mathrm{~mol} / \mathrm{l}$. For Zhang et al., activation energies are given for different temperature ranges, as indicated in the table.

\begin{tabular}{llll} 
Reference & Electrolyte & Conductivity & Activation energy $\left(E_{\text {act }}\right)$ \\
\hline Nyman et al. $(2008)^{4}$ & EC:EMC 3:7 wt & $0.95 \mathrm{~S} / \mathrm{m}\left(25^{\circ} \mathrm{C}\right)$ & \\
Zhang et al. $(2002)^{7}$ & EC:EMC 3:7 wt & $0.80 \mathrm{~S} / \mathrm{m}\left(21^{\circ} \mathrm{C}\right)$ & $17.20 \mathrm{~kJ} / \mathrm{mol}\left(-20^{\circ} \mathrm{C} / 62^{\circ} \mathrm{C}\right)$ \\
& & $0.95 \mathrm{~S} / \mathrm{m}\left(30^{\circ} \mathrm{C}\right)$ & $15.30 \mathrm{~kJ} / \mathrm{mol}\left(0^{\circ} \mathrm{C} / 62^{\circ} \mathrm{C}\right)$ \\
& & & $26.70 \mathrm{~kJ} / \mathrm{mol}\left(-50^{\circ} \mathrm{C} /-10^{\circ} \mathrm{C}\right)$ \\
Ecker et al. $(2015)^{35}$ & EC:EMC 1:1 wt & $0.96 \mathrm{~S} / \mathrm{m}\left(25^{\circ} \mathrm{C}\right)$ & $17.12 \mathrm{~kJ} / \mathrm{mol}$
\end{tabular}


(a)

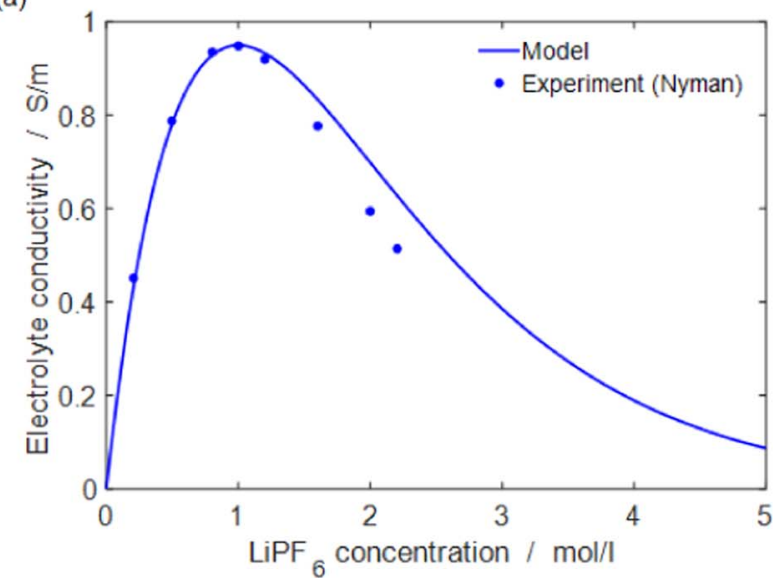

(b)

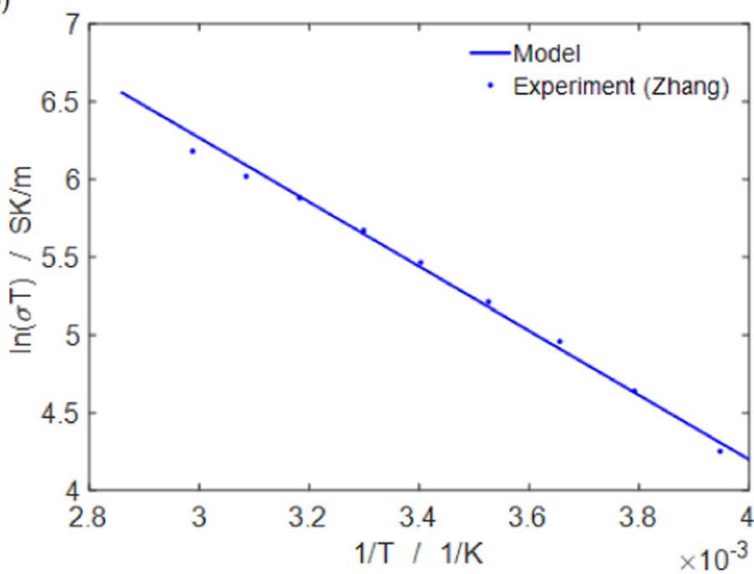

(c)

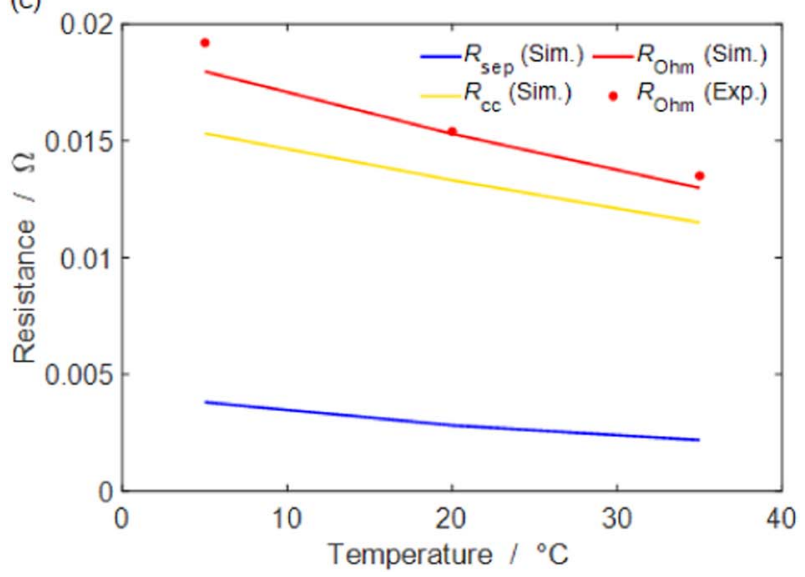

Figure 3. Electrolyte conductivity (a) as function of concentration for $T=$ $298 \mathrm{~K}$ (experiments from Nyman et al. ${ }^{4}$ ) and (b) as function of temperature at $c=1 \mathrm{~mol} / \mathrm{l}$ (experiments from Zhang et al.). ${ }^{7}$ The lines show the model prediction according to Eqs. 13, 14 and 11. (c) o resistance $R_{\mathrm{Ohm}}$ as sum of $R_{\text {sep }}$ and $R_{\text {cc }}$ for different temperatures at $50 \%$ SOC.

$R_{\text {sep }}$, and the current collection system $R_{\text {cc }}$ according to

$$
R_{\mathrm{Ohm}}=R_{\mathrm{sep}}+R_{\mathrm{cc}} \text {. }
$$

Figure $3 \mathrm{c}$ shows the simulated and experimental $R_{\mathrm{Ohm}}$ as well as its contributions according to Eq. 17 at different temperatures $\left(5^{\circ} \mathrm{C}, 20^{\circ} \mathrm{C}\right.$ and $\left.35^{\circ} \mathrm{C}\right)$. In our model the separator is thin and has a low tortuosity value, consequently we see $R_{\text {sep }}$ being lower than $R_{\mathrm{cc}}$. The fitted value of $\alpha_{\mathrm{cc}}=-0.009$ is slightly negative.


Figure 4. Solid-state diffusion coefficients of lithium within the three AM (a) $\mathrm{LCO}$, (b) NCA, (c) graphite at $20^{\circ} \mathrm{C}$.

Microscale: solid-state transport parameters.-All geometrical and transport parameters of the microscale (AM particle) are summarized in Table VI. Lithium diffusion inside the AM strongly influences cell behavior. We applied a literature research for concentration- and temperature-dependent diffusion coefficients and measured the average particle size via scanning electron microscopy (SEM). ${ }^{3}$ Figure 4 shows diffusion coefficients of intercalated lithium as function of intercalation stoichiometry for the three AM. Values in literature vary strongly, and our present choice has been carefully taken after reviewing several sources and considering data completeness.

For LCO, average diffusion coefficients vary from experimentally measured $10^{-16} \mathrm{~m}^{2} / \mathrm{s}$ in Xia et al. ${ }^{42}$ to $10^{-11} \mathrm{~m}^{2} / \mathrm{s}$ in Doyle and Fuentes. ${ }^{43}$ Sato et al. ${ }^{44}$ report values varying from $10^{-13}$ to $10^{-16} \mathrm{~m}^{2} / \mathrm{s}$ 
Table VI. Microscale: Transport parameters of lithium within the AM particles.

\author{
Parameter \\ Radius of cathode particles $r_{\mathrm{LCO}}$ \\ Diffusion coefficient of $\mathrm{Li}$ in $\mathrm{LCO} D_{\mathrm{Li}}$, LCO \\ Radius of cathode particles $r_{\mathrm{NCA}}$ \\ Diffusion coefficient of $\mathrm{Li}$ in NCA $D_{\mathrm{Li}}$, NCA \\ Radius of anode particles $r_{\mathrm{C}_{6}}$ \\ Diffusion coefficient of Li and graphite $D_{\mathrm{Li}, \mathrm{C}_{6}}$
}

by changing the transient method used for the measurement. Most commonly reported is a diffusion coefficient around $10^{-13} \mathrm{~m}^{2} / \mathrm{s} .{ }^{45-49}$ We decided then to use as reference the work from Van der Ven, ${ }^{50}$ in which the LCO diffusion coefficients have been calculated over the complete intercalation stoichiometry range by using first-principles electronic structure methods in combination with Monte Carlo simulations. This data is shown in Figure $4 \mathrm{a}$. Being obtained at $T=300 \mathrm{~K}$, we included an Arrhenius-type temperature dependence with an activation energy of $28.95 \mathrm{~kJ} / \mathrm{mol}$ as average of the various results obtained from Okubo et al. ${ }^{51}$

For NCA, reported diffusion coefficients values are more consistent, ${ }^{52-54}$ with experimentally measured values in the $10^{-14}-10^{-15} \mathrm{~m}^{2} / \mathrm{s}$ range. Here we chose the work from Dees et al., ${ }^{55}$ shown in Figure 4b, where GITT and EIS experiments have been conducted over a nearly complete intercalation stoichiometry range. As for LCO, we included an Arrhenius temperature dependence with an activation energy of $115.78 \mathrm{~kJ} / \mathrm{mol}$ as found by Amin. ${ }^{53}$

For graphite, diffusion coefficients vary greatly according to the characteristics of the material. Similar values around $10^{-15} \mathrm{~m}^{2} / \mathrm{s}$ were observed with different techniques by different authors. ${ }^{56-59}$ Other authors ${ }^{60,61}$ find slightly lower values in the so-called "natural graphite". Finally, we took as reference the work from Levi, ${ }^{62}$ where the diffusion was investigated using both PITT and EIS techniques. The values are shown in Figure 4c. They were also used in the models by Kupper. ${ }^{1}$ An activation energy of $44.0 \mathrm{~kJ} / \mathrm{mol}$ was used, as average between the two values experimentally measured (respectively with GITT - $48.9 \mathrm{~kJ} / \mathrm{mol}$ - and EIS - $40.8 \mathrm{~kJ} / \mathrm{mol}$ - methods) in Ecker et al. ${ }^{35}$
Value

$4.5 \cdot 10^{-6} \mathrm{~m}$
See Figure $4 \mathrm{a}$
$0.7 \cdot 10^{-6} \mathrm{~m}$
See Figure $4 \mathrm{~b}$
$1.075 \cdot 10^{-5} \mathrm{~m}$
See Figure $4 \mathrm{c}$

Reference

Measured $^{3}$
Calculated $^{50}+$ activation energy $^{51}$
Measured $^{3}$
Measured $^{55}+$ activation energy $^{53}$
Measured $^{3}$
Measured $^{62}+$ activation energy $^{35}$

Electrochemical parameters.-The electrochemical parameters include the rate coefficients of the three charge-transfer reactions (LCO, NCA and graphite), their activation energies, as well as doublelayer capacitances of both electrodes. These parameters were obtained by fitting simulated EIS data to experimental values at two different SOC $(20 \%, 50 \%)$ and three different temperatures $\left(5^{\circ} \mathrm{C}, 20^{\circ} \mathrm{C}, 35^{\circ} \mathrm{C}\right)$. The two SOC values were chosen for maximizing sensitivity toward the two blend cathode components (LCO, NCA). The activation energies were obtained from Arrhenius plots. The resulting values of the double layer capacitances are included in Table IV. The electrochemical rate coefficients for all AM are reported in Table VII. The resulting EIS fits will be discussed below.

Within the blend cathode, the two electrochemical reactions of LCO and NCA are assumed to take place in parallel. This allows the independent intercalation or deintercalation of the individual AM, the relative rates of which are governed by the differences in the respective rate constants. When the cell is at rest, the two reactions still can take place in parallel; as the overall cell current is zero at rest, electrons produced by one reaction must be consumed by the other reaction either at the same or at different local positions (on the $y$ scale), giving rise to inter-particle equilibration processes.

\section{Results and Discussion}

Thermo-electrochemical behavior over wide operation range.In Figure 5 to Figure 7 we show the macroscopically observable thermo-electrochemical behavior of the cell both in the frequency and time domains, which we use to compare to experimental data. (a)

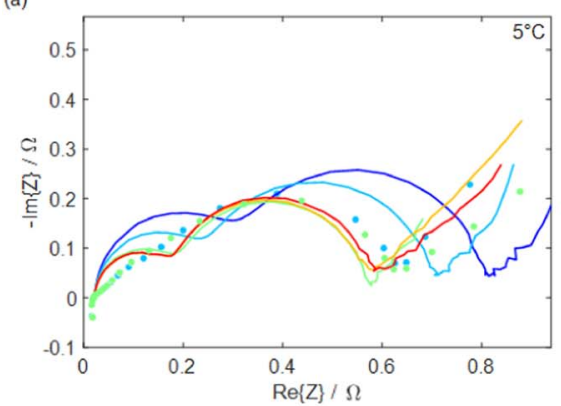

(b)


(c)

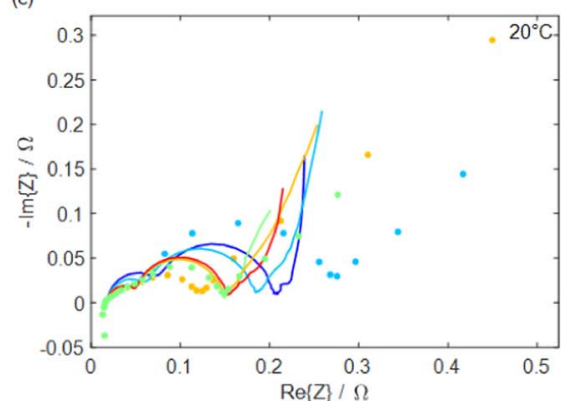

(d)

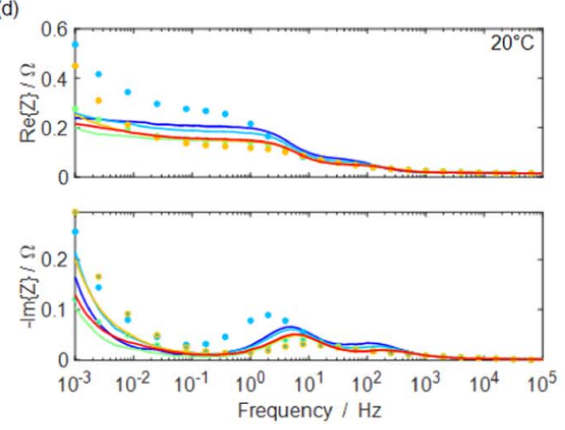

(e)

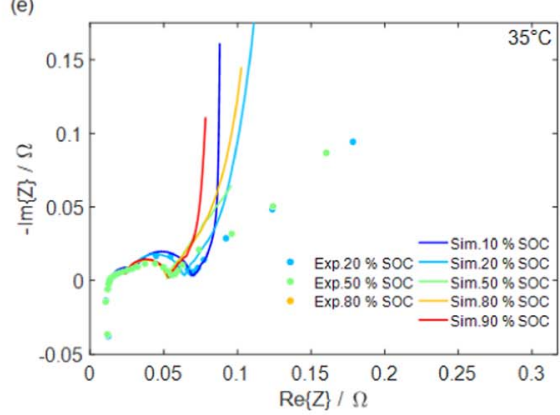

(f)
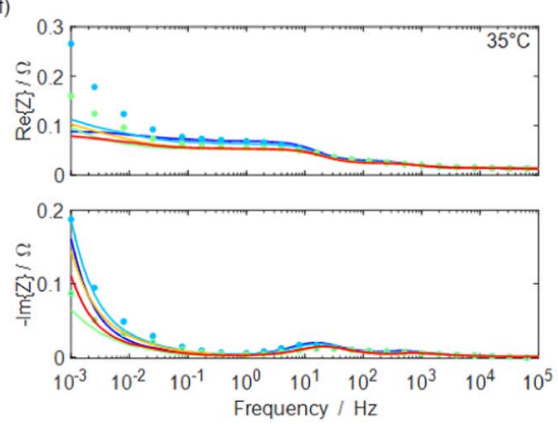

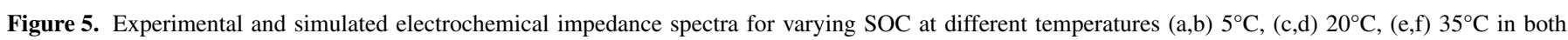
Nyquist $(\mathrm{a}, \mathrm{c}, \mathrm{e})$ and Bode $(\mathrm{b}, \mathrm{d}, \mathrm{f})$ representations. 
Table VII. Interfacial chemical reactions and rate coefficients, as obtained from fitting to EIS experiments. The symmetry factors are assumed.

\begin{tabular}{lllr} 
Interface & Reaction & $\begin{array}{l}\text { Exchange current } \\
\text { density factor } i^{00} / \mathrm{A} \cdot \mathrm{m}^{-2}\end{array}$ & $\begin{array}{l}\text { Activation energy } \\
E_{\text {act, }} / \mathrm{kJ} \cdot \mathrm{mol}^{-1}\end{array}$ \\
\hline $\mathrm{LCO} /$ electrolyte & $\mathrm{Li}^{+}[\mathrm{elyt}]+\mathrm{e}^{-}+\mathrm{V}[\mathrm{LCO}] \rightleftarrows \mathrm{Li}[\mathrm{LCO}]$ & $8.20 \cdot 10^{12}$ & $\begin{array}{l}\text { Symmetry } \\
\text { factor } \alpha_{\mathrm{f}}\end{array}$ \\
NCA/electrolyte & $\mathrm{Li}^{+}[\mathrm{elyt}]+\mathrm{e}^{-}+\mathrm{V}[\mathrm{NCA}] \rightleftarrows \mathrm{Li}[\mathrm{NCA}]$ & $2.63 \cdot 10^{10}$ & 0.5 \\
Graphite/electrolyte & $\mathrm{Li}^{+}[\mathrm{elyt}]+\mathrm{e}^{-}+\mathrm{V}\left[\mathrm{C}_{6}\right] \rightleftarrows \mathrm{Li}\left[\mathrm{C}_{6}\right]$ & $8.84 \cdot 10^{14}$ & 61.01 \\
\end{tabular}

A comparison of EIS simulations and measurements is shown in Figure 5. Simulations were carried out for frequencies from $10^{-3} \mathrm{~Hz}$ up to $10^{5} \mathrm{~Hz}$, SOCs of $10 \%, 20 \%, 50 \%, 80 \%$ and $90 \%$, and temperatures of $5^{\circ} \mathrm{C}, 20^{\circ} \mathrm{C}$ and $35^{\circ} \mathrm{C}$. Experiments were taken only at $20 \%$ and $50 \%$ SOC and, at $20^{\circ} \mathrm{C}$, also at $80 \%$ SOC. Before discussing the similarities and differences between experimental and simulated impedance spectra, it should be repeated (cf. above) that the only free fit parameters were the exchange current density factors $i^{00}$ and activation energies $E_{\text {act,f }}$ of the three charge-transfer reactions (cf. Table VII) as well as double-layer capacitances for both electrodes (cf. Table IV). All other model parameters were kept constant, including the diffusion coefficients. Furthermore, the EIS behavior is constrained by the physicochemical model. For example, despite its complexity and spatial resolution, the model generates perfect semicircles (as opposed to depressed semi-circles) for the electrodes. This is a typical illustration of the general difference between physicochemical models (many parameters but constrained by physical meaning and therefore often lesser agreement with experiment) and equivalent circuit models (fewer parameters, but more empirical and therefore often better agreement with experiments).

In Figure 5, both experiment and simulation show three features: (i) a small semi-circle at high frequency (approx. $100 \mathrm{~Hz}$ ) which can be assigned to the anode charge-transfer reaction and double layer, (ii) a larger, overlapping semi-circle at medium frequency (approx. $10 \mathrm{~Hz}$ ) which can be assigned to the cathode charge-transfer reaction and double-layer, and (iii) a Warburg-type feature at low frequency $(<0.1 \mathrm{~Hz})$ which can be assigned to lithium diffusion in the AM. There is qualitative agreement between model and experiment concerning the magnitude, frequency, temperature- and SOC-dependence of these features.

The simulations distinctly disagree with the experiments at low frequencies. They underpredict the Warburg branch and show a strong additional increase of the negative imaginary part toward very low frequencies $(<1 \mathrm{mHz})$ which is not present in the experiments. These results indicate that the solid-state diffusion coefficients used in the model are too high and have an incorrect stoichiometry and temperature dependence in comparison to the present experiments. Still, the diffusions coefficients used in the model were carefully selected based on an extensive literature review (cf. microscale parameterization Section). Most likely, the materials used in literature are different from those used in the present cell; the large scatter of diffusion coefficients observed in literature indicate that differences in the production process may indeed have a strong impact on particle-scale diffusion. Also morphology has a strong impact on diffusion behavior, where the present assumption of ideal spherical particles is clearly different compared to the true morphology observed by SEM. ${ }^{3}$

The improvement of the diffusion model is out of scope of the present study. Simple fitting of the diffusion coefficients is not possible, because the observed Warburg branch is a superposition of the diffusion of all three active materials and their different contributions could not be separated. The measurement of diffusion coefficients in the materials of the target cell is complex and requires dedicated experiments (disassembly of the cells, separation of the electrodes, assembly of half cells and measurement of diffusion via GITT, PITT or EIS ${ }^{63}$ and still probably would not be able to differentiate the blend materials. The integration of a more realistic morphology in the present P3D model (e.g., by using particle size distributions) represents a major model extension, ${ }^{64}$ coming along with the need of additional parameters. Having thus recognized the challenge of diffusion modeling, an improved parameterization and/or model extension will be subject of our future studies.

We will next discuss the time-domain behavior. In Figure 6 simulated $\mathrm{CCCV}$ discharge-charge cycles are compared with experimental data at different temperatures and C-rates. The results of our

(a)

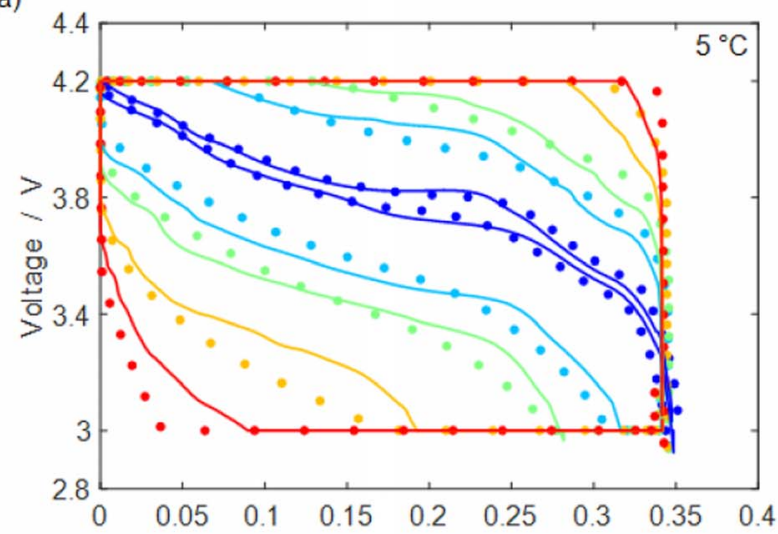

(b)

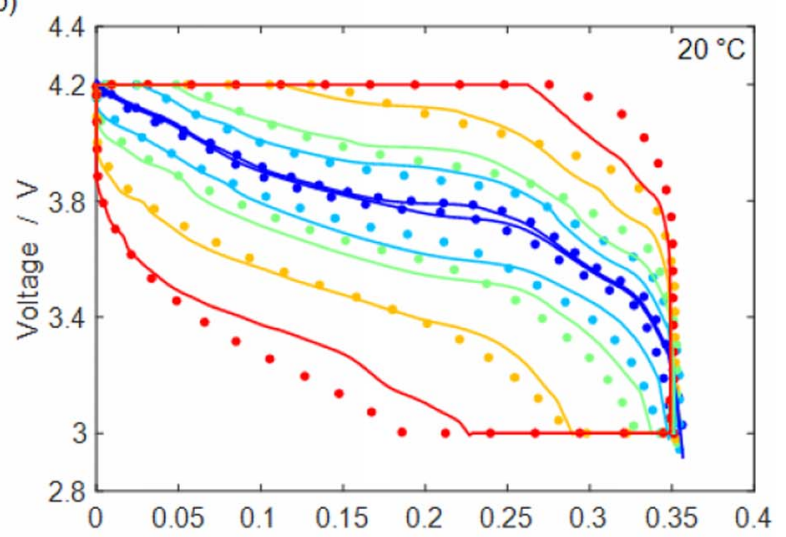

(c)

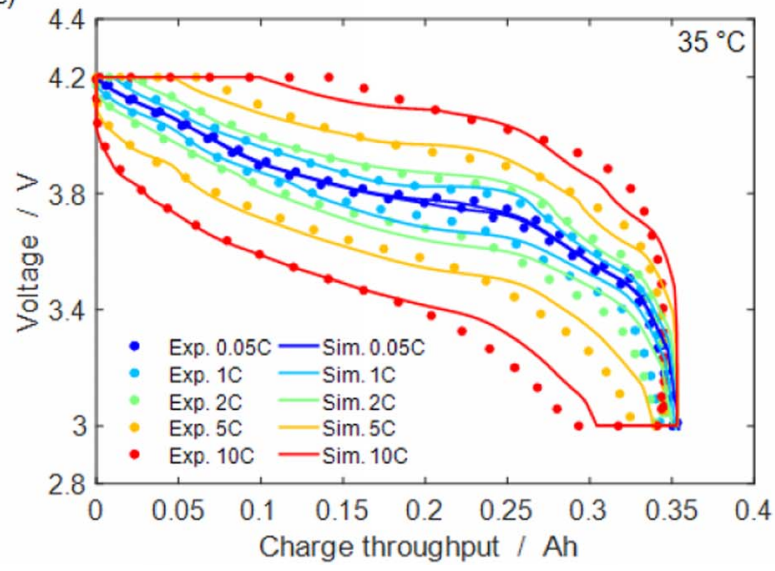

Figure 6. Experimental and simulated CCCV discharge/charge cycles at (a) $5^{\circ} \mathrm{C}$, (b) $20^{\circ} \mathrm{C}$, (c) $35^{\circ} \mathrm{C}$. 
(a)

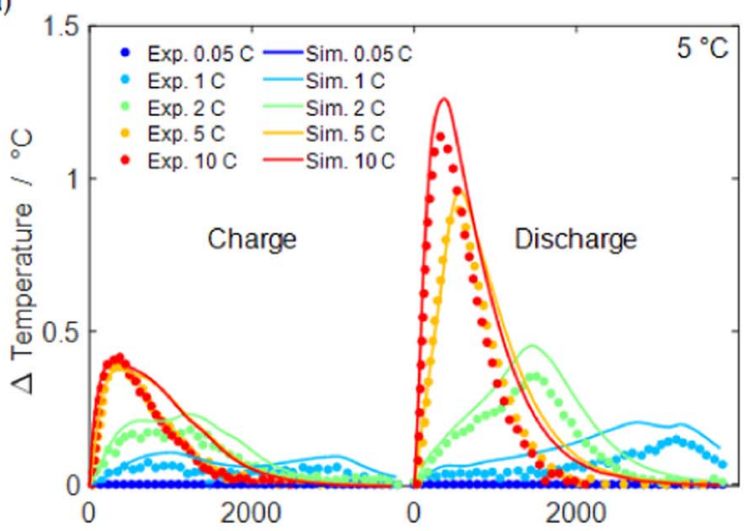

(b)

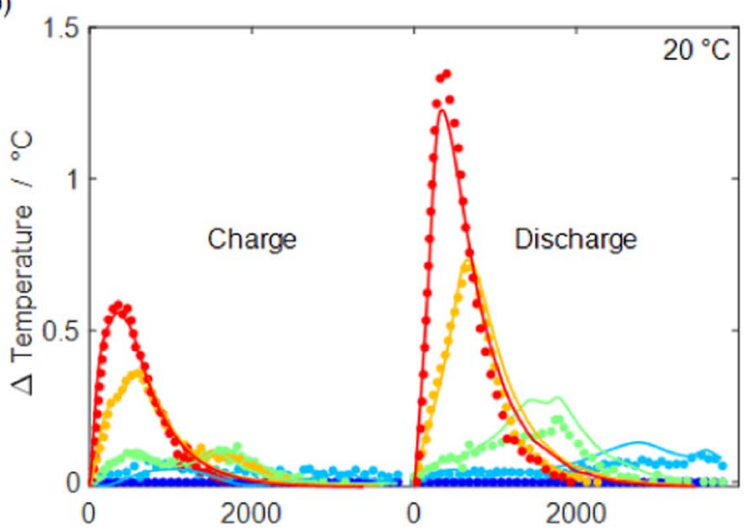

(c)

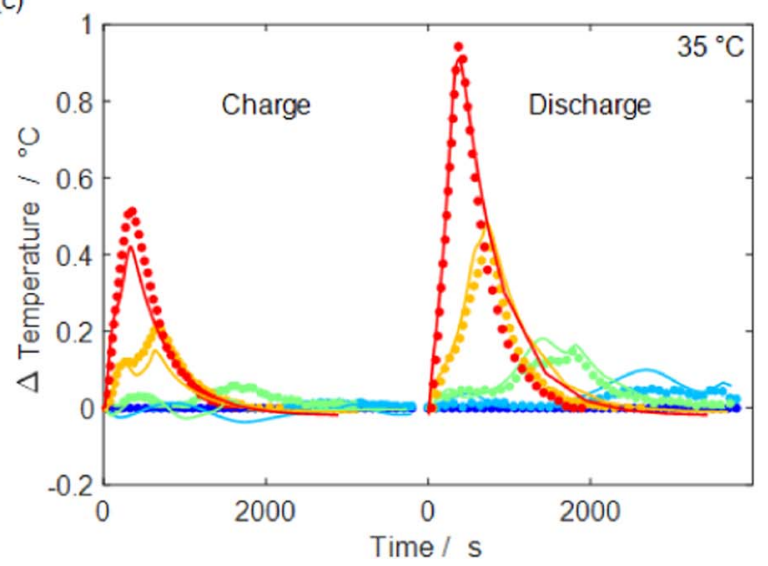

(d)

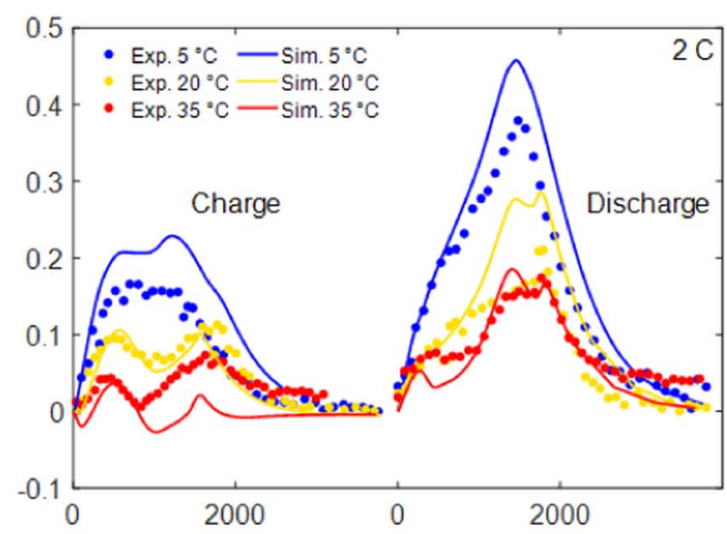

(e)

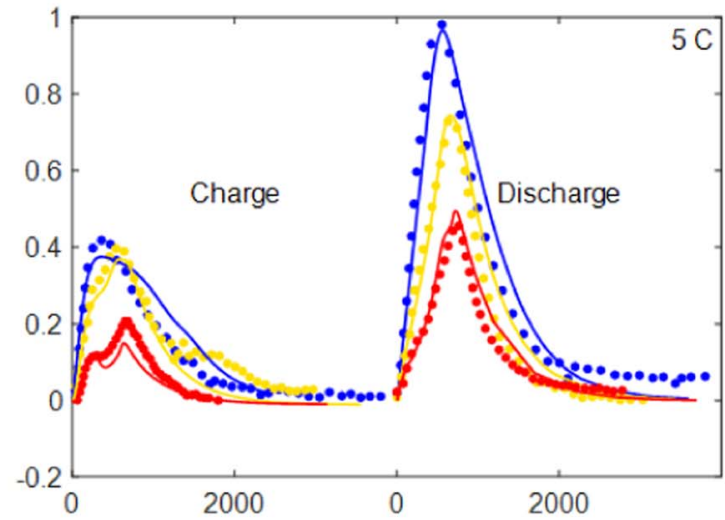

(f)

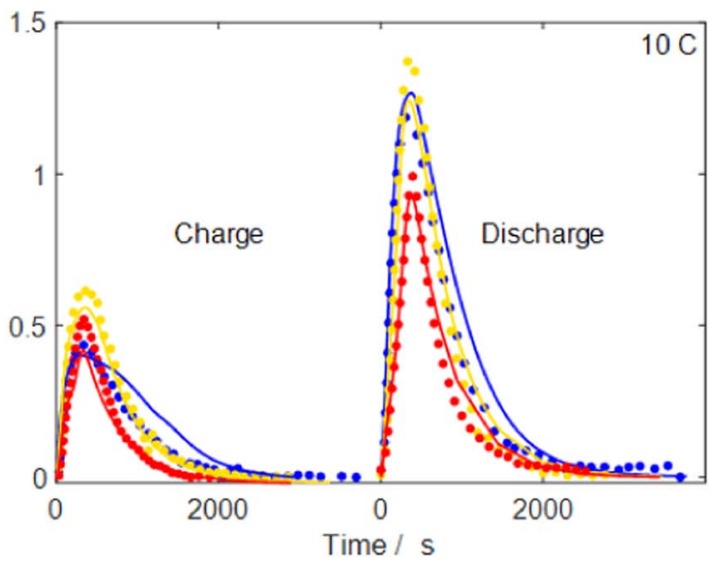

Figure 7. Experimental and simulated cell surface temperature. (a,b,c) different C-rates at (a) $5^{\circ} \mathrm{C}$, (b) $20^{\circ} \mathrm{C}$, (c) $35^{\circ} \mathrm{C}$ ambient temperature. (d-e) different ambient temperatures at (d) $2 \mathrm{C}$, (e) 5C, (f) $10 \mathrm{C}$.

simulations show a very good agreement with experiments at all Crates (here from $0.05 \mathrm{C}$ to $10 \mathrm{C}$ ) and shows a high reproducibility even at different temperatures. Therefore, using a suitable set of thermodynamic data and parameterizing the kinetics with EIS for all the three AM, our model is able to simulate the behavior of the experimental cell over the complete investigated range of C-rates and temperatures.

Figure 7 shows the temperature of the aluminum plate surface during the CCCV cycles for all investigated C-rates and temperatures. Again, simulations are compared to experimental data, and both show a very good agreement over the complete investigated range of conditions. Simulations quantitatively reproduce the height and shape of temperature peaks during both charge and discharge, including the cooling during rest. The temperature increase is rather small $\left(<1.5^{\circ} \mathrm{C}\right.$ even at $10 \mathrm{C}$ ), which is owed to the high heat capacity of the large aluminum end plates in comparison to the relatively small cell heat capacity. It is interesting to note that the temperature shows a signifi- cant difference between charge and discharge. This is caused by both the reversible heat production (resulting in heat consumption during charge) and the more extended $\mathrm{CV}$ phase during charge.

Overall, the macroscopic thermo-electrochemical behavior of the virtual cell is good agreement with experimental data over the complete investigated range of SOCs, C-rates and temperatures both in the time-domain and frequency-domain. It is worth noting that this is achieved with one single set of model parameters. The main discrepancy overserved is the low-frequency EIS behavior associated with solid-state diffusion. A more detailed investigation has to be subject of future studies. Nevertheless, we believe that the model can be considered as validated. It will be used in the following to analyze internal states not observable by macroscopic measurements.

P3D distribution of internal states.-The model allows insight into internal states of the cell on all pseudo-three-dimensional scales, 

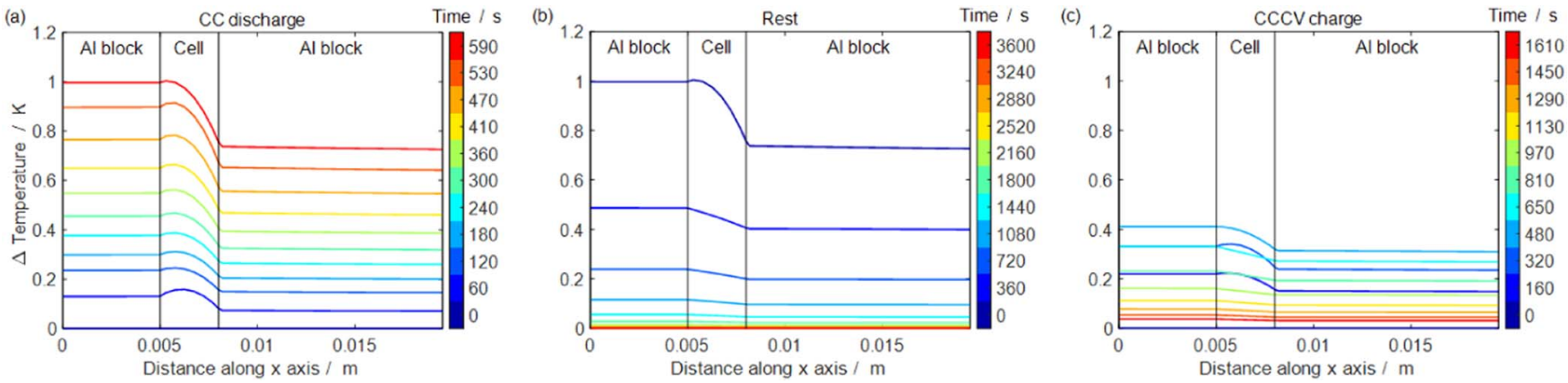

Figure 8. Macroscale: Simulated temperature distribution for a $5 \mathrm{C} \mathrm{CC}$ discharge, $1 \mathrm{~h}$ rest, $\mathrm{CCCV}$ charge at $20^{\circ} \mathrm{C}$ ambient temperature.

which will be discussed in this Section. All data show a 5C CC discharge, $1 \mathrm{~h}$ rest, and $5 \mathrm{C} \mathrm{CCCV}(\mathrm{C} / 20$ cutoff $)$ charge at $20^{\circ} \mathrm{C}$ ambient temperature, starting from a fully-charged cell.

On the macroscopic scale (cell and aluminum plates), the temperature profiles are shown in Figure 8. Here and throughout the remainder of this Section, the left panels show the 5C CC discharge, the middle panels the rest phase, and the right panels the 5C CCCV charge. During the discharge a temperature increase up to $1.5 \mathrm{~K}$ is present within the cell. Caused by the different thickness of the aluminum plates, also a temperature difference of $0.48 \mathrm{~K}$ between the left $(x=$ $5 \mathrm{~mm})$ and right $(x=8 \mathrm{~mm})$ interface between aluminum plate and cell is observed. A nearly isothermal behavior is visible within the aluminum plates due to their comparatively high thermal conductivity. The temperature difference within the cell itself reaches $0.52 \mathrm{~K}$ at the end of the discharge. The temperature difference inside the cell is quite low in comparison to Erhard et al. ${ }^{65}$ who measured up to $5 \mathrm{~K}$ difference between center and surface of a LFP/graphite cylindrical cell. This is mainly caused by the different dimension of the used cells and the presence of the aluminum plates which result in a very high heat capacity of the system and therefore the introduced heat in comparison to the heat capacity of the system is much lower. During the $1 \mathrm{~h}$ rest (Figure 8, middle panel), the temperature completely relaxes to ambient temperature. During charge (right panel), the temperature increase is lower than during discharge, as already discussed above (Figure 7).

On the mesoscopic scale (electrode pair), the spatiotemporal behavior of the internal states is shown in Figure 9. The concentration of $\mathrm{Li}^{+}$and $\mathrm{PF}_{6}^{-}$ions (both with identical value, in respect of charge neutrality) in the electrolyte during discharge is shown in Figure 9a. A gradient is visible between negative electrode (high concentration) and
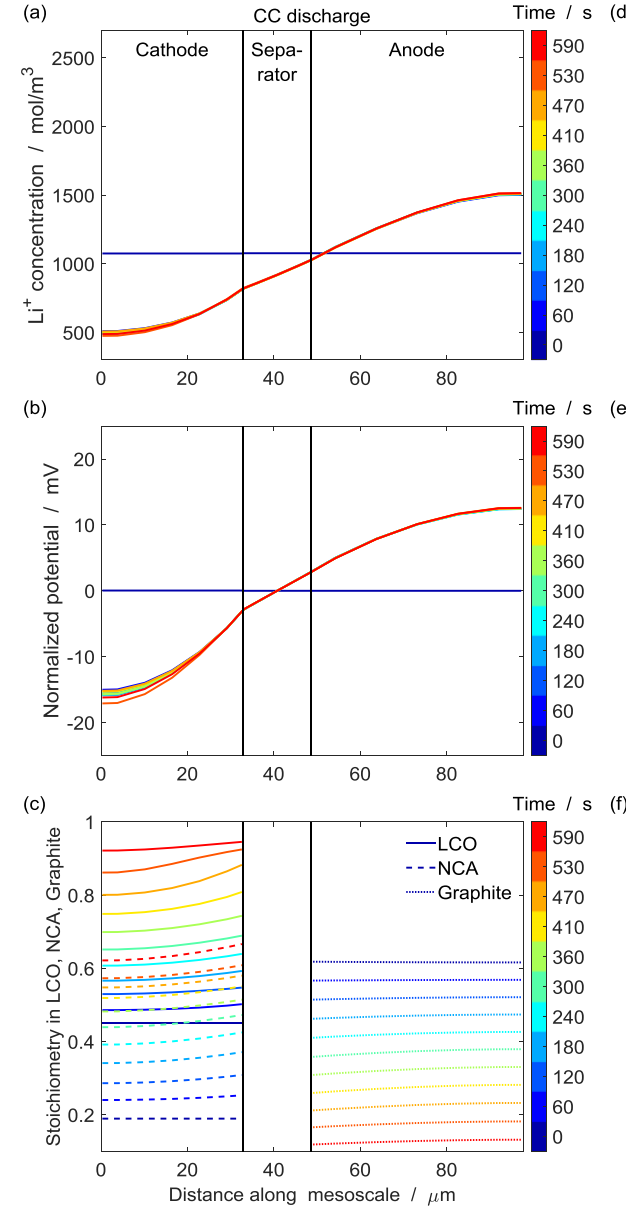
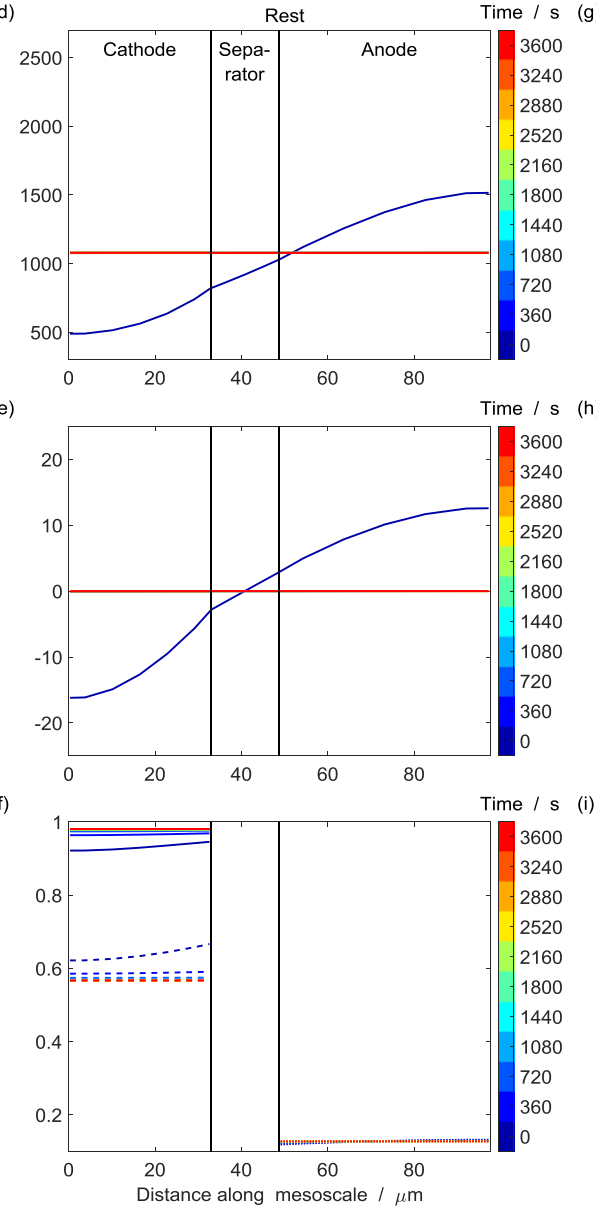
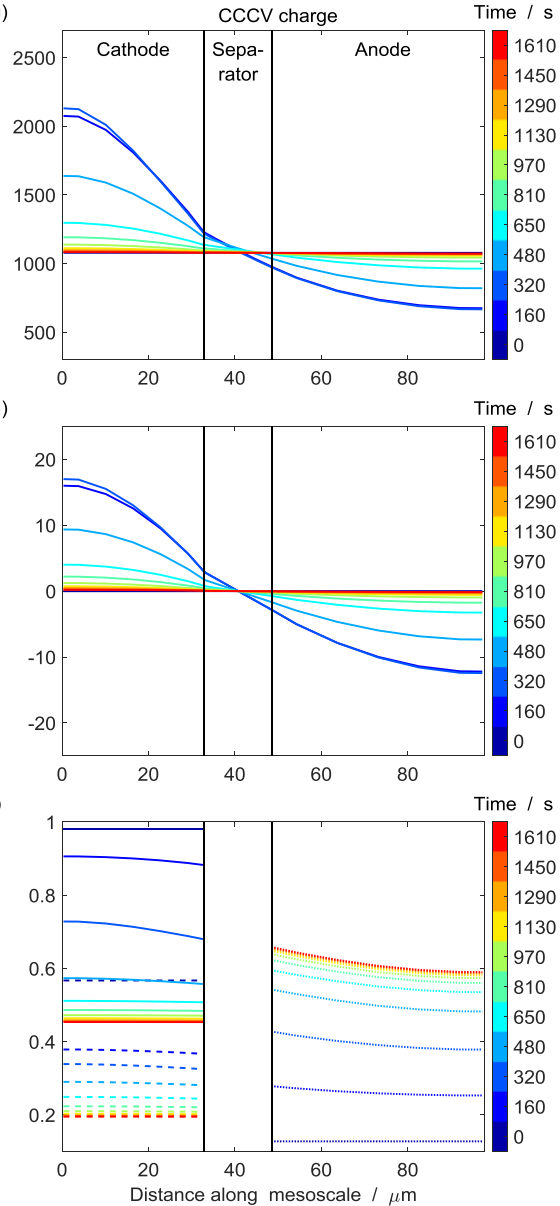

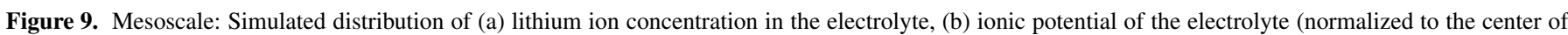
the separator), and (c) average lithium bulk stoichiometry in the AM for a $5 \mathrm{C} \mathrm{CC}$ discharge, $1 \mathrm{~h}$ rest, $\mathrm{CCCV}$ charge at $20^{\circ} \mathrm{C}$. 
positive electrode (low concentration), consistent with the formation and consumption of $\mathrm{Li}^{+}$at the anode and at the cathode, respectively. After a fast-initial variation, concentrations keep quite stable during all the $\mathrm{CC}$ discharge. Figure $9 \mathrm{~b}$ shows the electric-potential distribution in the electrolyte. The potential was normalized to the value at the center of the separator to make the small gradient (ca. 10-20 mV) visible. The potential is increasing from the positive to the negative electrode, as expected, with a spatial gradient visible inside both electrodes and a small temporal gradient toward more negative values in the most outside layers of the cathode. Added to the diffusive flux originating from the concentration gradient (Figure $9 \mathrm{a}$ ) $\mathrm{Li}^{+}$is here driven by a migration flux in the same direction from the negative to the positive electrode. For $\mathrm{PF}_{6}^{-}$, the migration flux due to the potential gradient is in the opposite direction and cancelled by the diffusive flux, resulting in a net zero flux for the $\mathrm{PF}_{6}^{-}$ion. The combined fluxes thus satisfy the conditions for both charge neutrality and net $\mathrm{Li}^{+}$transport. Figure $9 \mathrm{c}$ shows the lithium stoichiometry in the AM (LCO and NCA on the left and graphite on the right). At the positive electrode, the stoichiometry increases (lithium intercalation), while at the negative electrode it decreases (lithium de-intercalation) during the complete discharge period. The data show a spatial gradient of the stoichiometry - that is, a spatial distribution of the local SOC - which is more pronounced at the positive electrode for LCO than for NCA, with the highest values close to the separator interface. At the end of the CC discharge, the stoichiometry limits have not yet been reached for all the AM, as we can see by comparison with the stoichiometry range in Table IV.

A rest phase follows the $\mathrm{CC}$ discharge and is illustrated in Figures 9d, 9e, 9f. The ion concentration and the electric-potential distribution quickly relax to a spatiotemporally constant value, while slow changes are observed in the lithium stoichiometries in the cathode. These are related to the equilibration of the two blend components (NCA and LCO), which will be further discussed below. At the same time, a small internal spatial rearrangement is visible at the graphite anode from the layers close to the current collector to the ones at the electrode/separator interface. Figures $9 \mathrm{~g}$, 9h, 9i show the behavior during CCCV charge. For the $\mathrm{Li}^{+}$concentration (Figure 9g), the situation is reversed to what seen in Figure 9a, with the high values from $\mathrm{Li}^{+}$formed at the cathode and low values from $\mathrm{Li}^{+}$consumed at the anode, progressively decreasing to the equilibrium value during the CV phase. The electric potential (Figure 9h) shows a similar behavior. Figure 9i shows the complete de-intercalation of LCO and NCA to the lower stoichiometry limits, while the graphite gets well intercalated at the anode. A spatial gradient is here clearly visible in both electrodes, being present in the graphite anode even at the end of charge, indicating that the cell is not completely equilibrated at end of the CV phase.

Finally, on the microscopic (particle) scale, Figure 10 shows the distribution of lithium stoichiometries inside the AM particles. These data were taken for particles close to the electrodes/separator interface ( $y=32.9 \mu \mathrm{m}$ for the cathode and $y=48.6 \mu \mathrm{m}$ for the anode). During the CC discharge, the distribution of lithium stoichiometry inside LCO (Figure 10a) is spatially quite uniform for most of the discharge and shows only slight gradient with higher values at the particle surface $(z=0 \mu \mathrm{m})$ toward the end of discharge. NCA (Figure 10b) also shows a spatially uniform distribution but is only partially intercalated and reaches a maximum stoichiometry of 0.675 at the particle surface, rather inferior to the stoichiometry limits. The stoichiometry of lithium in graphite (Figure 10c) continuously decreases during CC discharge,
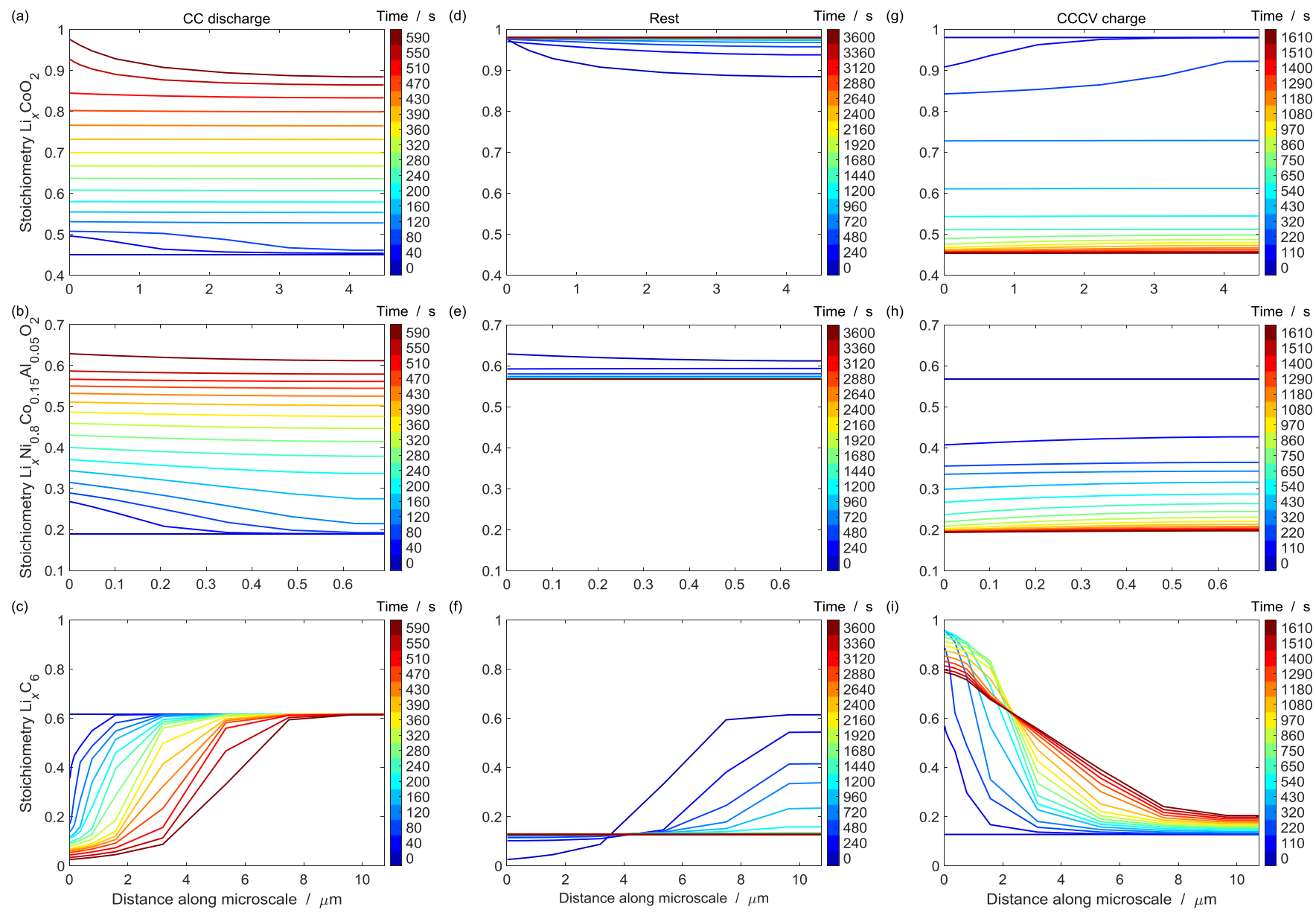

Figure 10. Microscale: Simulated distribution of intercalated lithium stoichiometry inside AM particles of (a) LCO, (b) NCA, (c) graphite for a 5C CC discharge, $1 \mathrm{~h}$ rest, $\mathrm{CCCV}$ charge at $20^{\circ} \mathrm{C}$. The data were taken for particles close to the electrode/separator interfaces. 
starting at the particle surface and showing a strong spatial gradient of the stoichiometry with no de-intercalation happening at the center of the particle $(\sim 10 \mu \mathrm{m})$.

The rest phase (Figures $10 \mathrm{~d}, 10 \mathrm{e}, 10 \mathrm{f}$ ) is showing stoichiometry rearrangements both within the particles as well as between the particles in the blend cathode, as similarly seen in Figure $9 \mathrm{f}$ at the electrode pair scale. In Figure 10d we see LCO spatial gradient slowly disappearing to reach finally a uniform higher stoichiometry value of 0.98 . An equilibrium is reached internally to the positive electrode, with NCA particles (Figure 10e) getting de-intercalated to a spatially uniform lower stoichiometry on behalf of LCO, which will be further discussed below. In graphite (Figure 10f), the lithium stoichiometry rearranges to reach a spatially uniform value, with a strong decrease in the particle center on behalf an increase in in the outer regions.

During CCCV charge (Figures 10g, 10h, 10i), the behavior for all the particles is similar than during discharge, however with opposite gradients. However, intra- and inter-particle equilibration already starts during the decreasing current of the $\mathrm{CV}$ phase. At the end of the $\mathrm{CV}$ phase, NCA and LCO are almost under equilibrium, while strong gradients remain within the graphite particles.

Blend cathode behavior.-An original feature of the present model is the ability to describe the behavior of blend electrodes. As already noted above, LCO and NCA show a complex inter-particle equilibration behavior, which is further analyzed in the present Section.

Figure 11 shows the relative lithium stoichiometries of the three $\mathrm{AM}$ (i.e., $X_{\mathrm{Li}}$ scaled to their respective ranges as given in Table IV) as function of charge throughput during a $5 \mathrm{C} \mathrm{CC}$ charge, $1 \mathrm{~h}$ rest, $\mathrm{CCCV}$ charge cycle for three different temperatures. For a fully-charged cell (0 Ah charge throughput), the graphite anode is fully lithiated and the NCA/LCO cathode fully delithiated. Graphite shows a linear delithiation/lithiation behavior upon cycling, i.e., the stoichiometry is directly proportional to the charge throughput. The blend cathode shows a nonlinear and dynamic behavior, which becomes more pronounced as the temperature increases. At $20^{\circ} \mathrm{C}$ (Figure $11 \mathrm{~b}$ ), for the first half of the discharge, NCA is lithiated slightly faster than LCO; in the second half of the discharge, LCO is lithiated significantly faster. This is due to the difference of half-cell potential curves of the two materials, where LCO shows a pronounced plateau at high degrees of lithiation (cf. Figure 2 and Ref. 3). At end of 5C discharge, the remaining SOC is $19 \%$, and the relative lithiation of LCO is significantly higher than that of NCA. During the $1 \mathrm{~h}$ rest time, the results show significant interparticle transfer of lithium from NCA to LCO, further increasing LCO stoichiometry. During subsequent charge, the difference in the degree of lithiation between LCO and NCA is even more pronounced than during discharge. At lower temperature $\left(5^{\circ} \mathrm{C}\right.$, Figure $\left.11 \mathrm{a}\right)$, only a minor part of the capacity is accessible during the $5 \mathrm{C} \mathrm{CC}$ discharge. At higher temperature $\left(35^{\circ} \mathrm{C}\right.$, Figure $\left.11 \mathrm{c}\right)$, almost the complete capacity is discharged; the nonlinearity of the blend materials is pronounced.

The results presented here and in the previous Section show that LCO and NCA are not under equilibrium during cycling, demonstrating the complex behavior of blend electrodes.

\section{Conclusions}

We have presented the development, parameterization and application of a pseudo-three-dimensional (P3D) lithium-ion cell model with blend cathode. A systematic approach toward parameterization was used, starting from equilibrium and then adding transport processes on all three scales as well as electrochemistry. The model was validated in frequency domain (using EIS) and time domain (using discharge/charge cycling) over a wide range of SOC, C-rates and temperatures. Simulations show a good agreement with experimental data with the exception of the low-frequency impedance feature related to intra-particle diffusion. Simulations were used to visualize the internal states on the P3D scales. States on all scales show significant gradients due to finite transport rates. The LCO/NCA blend cathode shows a particularly complex behavior with both intra-particle and inter-particle nonequilibria during cycling. The model thus provides a detailed in-
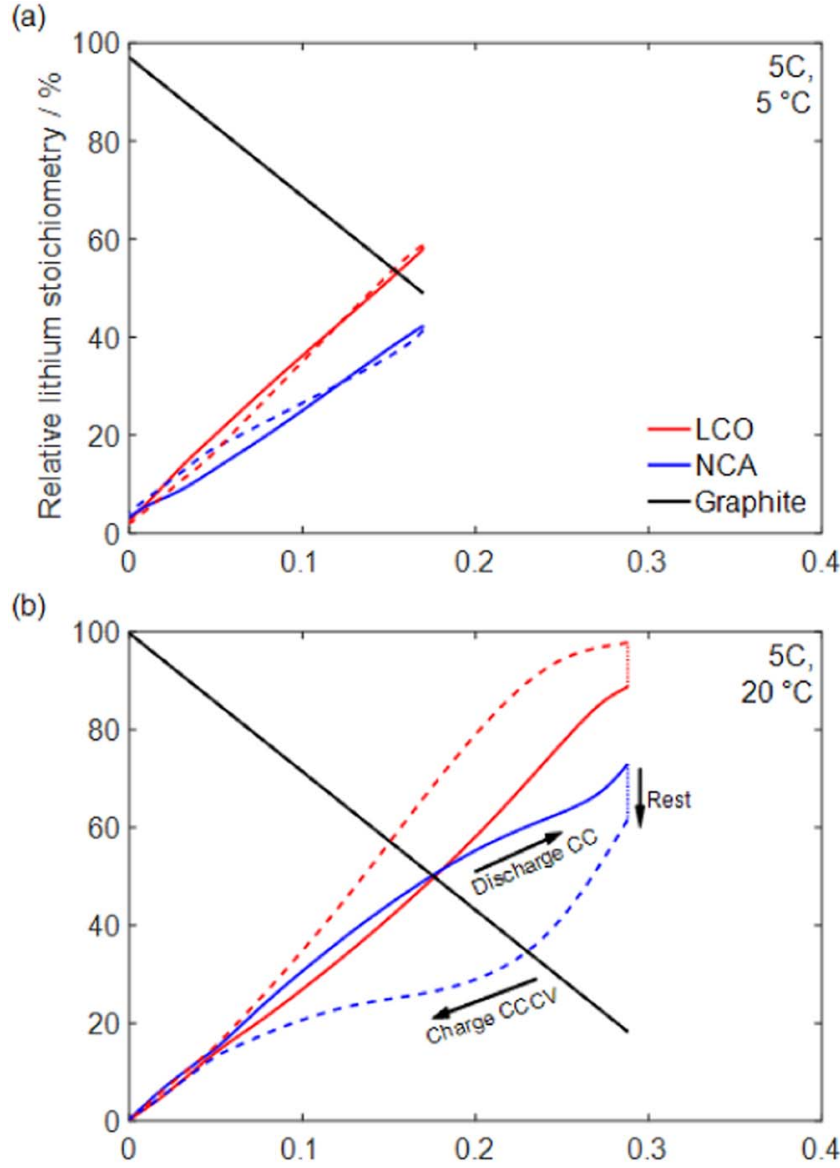

(c)

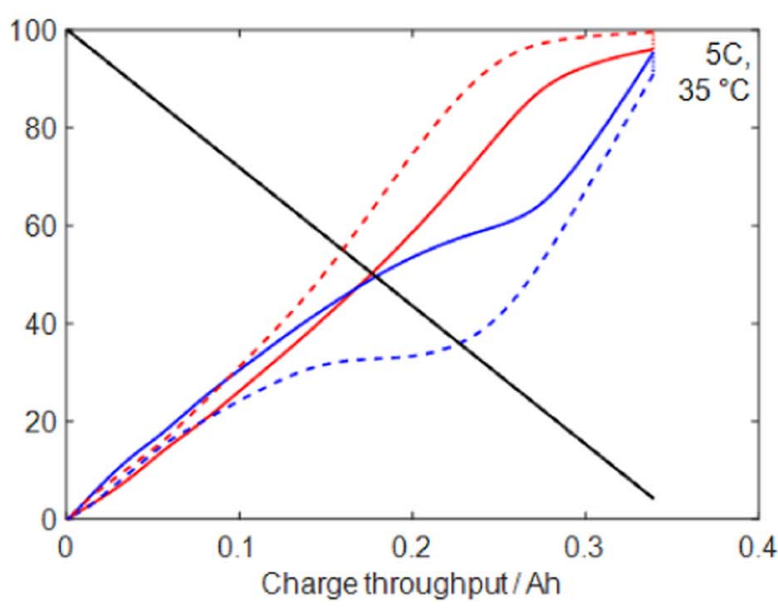

Figure 11. Simulated relative lithium stoichiometry in the three AM (LCO and NCA at the positive electrode, graphite at the negative electrode) for a $5 \mathrm{C}$ $\mathrm{CC}$ discharge, $1 \mathrm{~h}$ rest, $\mathrm{CCCV}$ charge at (a) $5^{\circ} \mathrm{C}$, (b) $20^{\circ} \mathrm{C}$ and (c) $35^{\circ} \mathrm{C}$.

sight into electrochemical and transport behavior of the lithium-ion cell.

\section{Acknowledgments}

This work was funded by the Deutsche Forschungsgemeinschaft (German Research Foundation, DFG) in the framework of the research training group SiMET - Simulation of Mechanical, Electrical and Thermal effects in Li-ion batteries (281041241/GRK 2218). The experimental measurements were funded by the German Ministry of Education and Research (BMBF) in the framework of the STABIL project (grant no. 03FH004PX5). 


\section{Appendix}

Symbol

A

$A^{\mathrm{V}}$

$A_{\mathrm{AM}, i}^{V}$

$a_{\mathrm{n}}$

$\alpha_{\mathrm{cc}}$

$C_{\mathrm{AM}, i}$
$c_{i}$

$C_{\mathrm{DL}}^{\mathrm{V}}$

$c_{\mathrm{P}}$

$D_{i}$

$D_{i}^{\text {eff }}$

$D_{\mathrm{Li}[\mathrm{AM}, i]}$

$E_{\mathrm{AM}, i}^{\mathrm{eq}}$

$E_{\text {act }, \mathrm{f}}$

F

$h_{\mathrm{Li}[\mathrm{AM}, i]}^{0}$

$h_{i}$

$i$

$i^{00}$

$j_{\mathrm{Li}[\mathrm{AM}, i]}$

$M_{\mathrm{Li}[\mathrm{AM}, i]}$

$M_{\mathrm{V}[\mathrm{AM}, i]}$

$N_{\text {AM }}$

$r$

$r_{\mathrm{AM}, i}$

$R$

$R_{\mathrm{cc}}$

$R_{\mathrm{Ohm}}$

$R_{\text {sep }}$

$\dot{s}_{\mathrm{Li}}^{V}[\mathrm{AM}, i]$

$\dot{s}_{\mathrm{V}[\mathrm{AM}, i]}^{V}$

$s_{i}$

$s_{\mathrm{Li}[\mathrm{AM}, i]}^{0}$

SOC elde

$t$

$t_{+}$

$T$

$V^{0}$

$x$

$X_{\mathrm{Li}[\mathrm{AM}, i]}$

$X_{\mathrm{Li}[\mathrm{AM}, i]}^{\mathrm{SOC}, 0} \cdots X_{\mathrm{Li}[\mathrm{AM}, i]}^{\mathrm{SOC}=1}$

$y$

$z$

$z$

$\alpha_{\mathrm{f}}$

$\epsilon$

$\varepsilon_{\mathrm{AM}, i}$

$\varepsilon_{\text {elyt }}$

$\lambda$

$\rho$

$\rho_{\mathrm{Li}}[\mathrm{AM}, i]$

$\rho_{\mathrm{AM}, i}$

$\sigma$

$\sigma_{\text {SEI }}$

$\tau$

$\tau_{\text {elyt }}$
Unit

$\mathrm{m}^{2}$

$\mathrm{m}^{2} \cdot \mathrm{m}^{-3}$

$\mathrm{m}^{2}$

1

1

F

$\mathrm{mol} \cdot \mathrm{m}^{-3}$

$\mathrm{F} \cdot \mathrm{m}^{-3}$

$\mathrm{J} \cdot \mathrm{g}^{-1} \cdot \mathrm{K}^{-1}$

$\mathrm{m}^{2} \cdot \mathrm{s}^{-1}$

$\mathrm{m}^{2} \cdot \mathrm{s}^{-1}$

$\mathrm{m}^{2} \cdot \mathrm{s}^{-1}$

V

$\mathrm{J} \cdot \mathrm{mol}^{-1}$

$\mathrm{C} \cdot \mathrm{mol}^{-1}$

$\mathrm{kJ} \cdot \mathrm{mol}^{-1}$

$\mathrm{kJ} \cdot \mathrm{mol}^{-1}$

1

$\mathrm{A} \cdot \mathrm{m}^{-2}$

$\mathrm{mol} \cdot \mathrm{m}^{-2} \cdot \mathrm{s}^{-1}$

$\mathrm{kg} \cdot \mathrm{mol}^{-1}$

$\mathrm{kg} \cdot \mathrm{mol}^{-1}$

1

$\mathrm{m}$

$\mathrm{m}$

$\mathrm{J} \cdot \mathrm{K}^{-1} \cdot \mathrm{mol}^{-1}$

$\Omega \cdot \mathrm{m}^{2}$

$\Omega \cdot \mathrm{m}^{2}$

$\Omega \cdot \mathrm{m}^{2}$

$\mathrm{mol} \cdot \mathrm{m}^{-3} \cdot \mathrm{s}^{-1}$

$\mathrm{mol} \cdot \mathrm{m}^{-3} \cdot \mathrm{s}^{-1}$

$\mathrm{J} \cdot \mathrm{mol}^{-1} \cdot \mathrm{K}^{-1}$

$\mathrm{J} \cdot \mathrm{mol}^{-1} \cdot \mathrm{K}^{-1}$

1

s

K

V

$\mathrm{m}$

1

$\mathrm{W} \cdot \mathrm{m}^{-2} \cdot \mathrm{K}^{-1}$

1

1

1

$\mathrm{W} \cdot \mathrm{m}^{-1} \cdot \mathrm{K}^{-1}$

$\mathrm{kg} \cdot \mathrm{m}^{-3}$

$\mathrm{kg} \cdot \mathrm{m}^{-3}$

$\mathrm{kg} \cdot \mathrm{m}^{-3}$

$\mathrm{S} \cdot \mathrm{m}^{-1}$

$\mathrm{S} \cdot \mathrm{m}^{-1}$

1

1
Meaning

Active electrode area

Volume-specific surface area

AM specific surface area

Equation parameters

Slope in Eq. 16

Individual overall capacity of the active material

Concentration of species $i$ in a bulk phase

Volume-specific double-layer capacitance

Specific heat capacity

Diffusion coefficient of species $i$

Effective diffusion coefficient of species $i$

Diffusion coefficient of lithium in active material

Half-cell potential vs. lithium metal

Activation energy of forward reaction

Faraday's constant

Molar enthalpy of intercalated lithium in active material

Molar enthalpy of species $i$

Index of species

Exchange current density factor

Boundary flux at the particle/electrolyte interface

Molar mass of lithiated active material

Molar mass of delithiated active material

Number of active materials

Radial position in activate material particle

Radius of active material particle

Ideal gas constant

Area-specific global resistance of current collection system

Area-specific ohmic part of the impedance

Area-specific electrolyte resistance in the separator

Volumetric source term of lithium in active material

Volumetric source term of vacancies in active material

Molar entropy of species $i$

Molar entropy of intercalated lithium in active material

Overall State-Of-Charge of an electrode

Time

Transference number of cation

Temperature

Open-circuit voltage

Spatial position in dimension of battery thickness

Lithium mole fraction

Stoichiometry range of lithium in the active material

Spatial position in dimension of electrode-pair thickness

Spatial position in dimension of particle thickness

Number of electron transferred in charge-transfer reaction

Heat transfer coefficient

Symmetry factor of forward reaction

Emissivity of the cell surface

Volume fraction

Volume fraction of the active material

Volume fraction of the electrolyte (porosity)

Thermal conductivity

Density

Density of the lithiated active material

Density of the delithiated active material

Electrolyte conductivity

Electrical conductivity of SEI

Geometric tortuosity

Geometric tortuosity of the electrolyte

*Units of mol, $\mathrm{m}$ and s depending on reaction stoichiometry. 


\section{ORCID}

Serena Carelli (D https://orcid.org/0000-0001-8959-6813

\section{References}

1. C. Kupper and W. G. Bessler, J. Electrochem. Soc., 164(2), A304 (2017).

2. A. A. Franco, M. L. Doublet, and W. G. Bessler, Editors, Physical Multiscale Modeling and Numerical Simulation of Electrochemical Devices for Energy Conversion and Storage: From Theory to Engineering to Practice, London, Heidelberg, New York, Dordrecht, Springer (2016).

3. M. Mayur, M. C. Yagci, S. Carelli, P. Margulies, D. Velten, and W. G. Bessler, Physical Chemistry Chemical Physics, submitted (2019).

4. A. Nyman, M. Behm, and G. Lindbergh, Electrochim. Acta, 53(22), 6356 (2008).

5. A. A. Franco, RSC Adv., 3(32), 13027 (2013).

6. M. Doyle, T. F. Fuller, and J. Newman, J. Electrochem. Soc., 140(6), 1526 (1993),

7. S. S. Zhang, K. Xu, J. L. Allen, and T. R. Jow, J. Power Sources, 110(1), 216 (2002)

8. S. Tippmann, D. Walper, L. Balboa, B. Spier, and W. G. Bessler, J. Power Sources, 252, 305 (2014).

9. E. Prada, D. Di Domenico, Y. Creff, J. Bernard, V. Sauvant-Moynot, and F. Huet, J. Electrochem. Soc., 159(9), A1508 (2012).

10. P. W. C. Northrop, M. Pathak, D. Rife, S. De, S. Santhanagopalan, and V. R. Subramanian, J. Electrochem. Soc., 162(6), A940 (2015).

11. A. Awarke, S. Pischinger, and J. Ogrzewalla, J. Electrochem. Soc., 160(1), A172 (2012).

12. J. Christensen, D. Cook, and P. Albertus, J. Electrochem. Soc., 160(11), A2258 (2013).

13. G.-H. Kim, K. Smith, K.-J. Lee, S. Santhanagopalan, and A. Pesaran, J. Electrochem Soc., 158(8), A955 (2011).

14. S. B. Chikkannanavar, D. M. Bernardi, and L. Liu, J. Power Sources, 248, 91 (2014).

15. C. Heubner, T. Liebmann, M. Schneider, and A. Michaelis, Electrochim. Acta, 269, 745 (2018).

16. T. Kobayashi, N. Kawasaki, Y. Kobayashi, K. Shono, Y. Mita, and H. Miyashiro, $J$. Power Sources, 245, 1 (2014).

17. N. S. Hochgatterer, M. R. Schweiger, S. Koller, P. R. Raimann, T. Wöhrle, C. Wurm, and M. Winter, Electrochem. Solid-State Lett., 11(5), A76 (2008).

18. P. Albertus, J. Christensen, and J. Newman, J. Electrochem. Soc., 156(7), A606 (2009).

19. S. Jung, J. Power Sources, 264, 184 (2014).

20. Z. Mao, M. Farkhondeh, M. Pritzker, M. Fowler, and Z. Chen, J. Electrochem. Soc., 163(3), A458 (2016).

21. A. Rodríguez and G. L. Plett, Journal of Energy Storage, 11, 219 (2017).

22. W. A. Appiah, J. Park, L. van Khue, Y. Lee, J. Choi, M.-H. Ryou, and Y. M. Lee, Electrochim. Acta, 187, 422 (2016).

23. M. Ecker, S. Kabitz, I. Laresgoiti, and D. U. Sauer, J. Electrochem. Soc., 162(9), A1849 (2015).

24. D. Goodwin, H. K. Moffat, and R. L. Speth, Cantera: An Object-Oriented Software Toolkit For Chemical Kinetics, Thermodynamics, And Transport Processes. Version 2.5.0, www.cantera.org (2019).

25. C. Kupper, B. Weißhar, S. Rißmann, and W. G. Bessler, J. Electrochem. Soc., 165(14), A3468 (2018).

26. C. Kupper, S. Spitznagel, H. Döring, M. A. Danzer, C. Gutiérrez, A. Kvasha, and W. G. Bessler, Electrochimica Acta, 306, 209 (2019).

27. M. Mayur, S. C. DeCaluwe, B. L. Kee, and W. G. Bessler, Electrochim. Acta, submitted (2019)

28. R. Ehrig, U. Nowak, L. Oeverdieck, and P. Deuflhard, in High performance scientific and engineering computing. Lecture notes in computational science and engineering, H.-J. Bungartz, F. Durst, and C. Zenger, Editors, p. 233, Springer (1999)

29. P. Deuflhard, E. Hairer, and J. Zugck, Numer. Math., 51(5), 501 (1987).

30. W. G. Bessler, J. Electrochem. Soc., 154, B1186 (2007).

31. Y. Reynier, J. Graetz, T. Swan-Wood, P. Rez, R. Yazami, and B. Fultz, Phys. Rev. B, 70(17), 753 (2004)

32. D. K. Karthikeyan, G. Sikha, and R. E. White, J. Power Sources, 185(2), 1398 (2008).
33. F. Hall, S. Wußler, H. Buqa, and W. G. Bessler, J. Phys. Chem. C, 120(41), 23407 (2016).

34. S. Basu, R. S. Patil, S. Ramachandran, K. S. Hariharan, S. M. Kolake, T. Song, D. Oh, T. Yeo, and S. Doo, J. Power Sources, 283, 132 (2015).

35. M. Ecker, T. K. D. Tran, P. Dechent, S. Kabitz, A. Warnecke, and D. U. Sauer, J. Electrochem. Soc., 162(9), A1836 (2015).

36. Y. F. Reynier, R. Yazami, and B. Fultz, J. Electrochem. Soc., 151(3), A422 (2004).

37. A. Loges, S. Herberger, P. Seegert, and T. Wetzel, J. Power Sources, 336, 341 (2016).

38. A. Loges, S. Herberger, D. Werner, and T. Wetzel, J. Power Sources, 325, 104 (2016)

39. C. Capiglia, Y. Saito, H. Kageyama, P. Mustarelli, T. Iwamoto, T. Tabuchi, and H. Tukamoto, J. Power Sources, 81-82, 859 (1999).

40. J. Newman, K. E. Thomas, H. Hafezi, and D. R. Wheeler, J. Power Sources, 119-121, 838 (2003).

41. C. Czeslik, H. Seemann, and R. Winter, Basiswissen Physikalische Chemie, StudienbucherChemie, Vieweg+TeubnerVerlag (2010).

42. H. Xia, Y. S. Meng, L. Lu, and G. Ceder, http://hdl.handle.net/1721.1/35827.

43. M. Doyle and Y. Fuentes, J. Electrochem. Soc, 150(6), A706 (2003).

44. H. Sato, D. Takahashi, T. Nishina, and I. Uchida, J. Power Sources, 68, 540 (1997).

45. K. Mizushima, P. Jones, P. Wiseman, and J. Goodenough, Solid State Ionics, 3-4, 171 (1981).

46. A. Honders, J. Derkinderen, A. Vanheeren, J. Dewit, and G. Broers, Solid State Ionics, 15(4), 265 (1985).

47. M. Thomas, P. Bruce, and J. Goodenough, Solid State Ionics, 17(1), 13 (1985).

48. J. Barker, R. Pynenburg, R. Koksbang, and M. Y. Saidi, Electrochim. Acta, 41(15), 2481 (1996).

49. Y.-I. Jang, B. J. Neudecker, and N. J. Dudney, J. Electrochem. Soc., 4(6), A74 (2001)

50. A. Van der Ven, Electrochem. Solid-State Lett., 3(7), 301 (1999).

51. M. Okubo, Y. Tanaka, H. Zhou, T. Kudo, and I. Honma, The journal of physical chemistry. B, 113(9), 2840 (2009).

52. D. P. Abraham, S. Kawauchi, and D. W. Dees, Electrochim. Acta, 53(5), 2121 (2008).

53. R. Amin, D. B. Ravnsbaek, and Y.-M. Chiang, J. Electrochem. Soc., 162(7), A1163 (2015).

54. K. Kleiner, J. Melke, M. Merz, P. Jakes, P. Nagel, S. Schuppler, V. Liebau, and H. Ehrenberg, ACS Appl. Mater. Interfaces, 7(35), 19589 (2015).

55. D. W. Dees, K. G. Gallagher, D. P. Abraham, and A. N. Jansen, J. Electrochem. Soc., 160(3), A478 (2013)

56. P. Yu, J. Electrochem. Soc., 146(1), 8 (1999).

57. K. Persson, V. A. Sethuraman, L. J. Hardwick, Y. Hinuma, Y. S. Meng, van der Ven, Anton, V. Srinivasan, R. Kostecki, and G. Ceder, J. Phys. Chem. Lett., 1(8), 1176 (2010).

58. T. L. Kulova, A. M. Skundin, E. A. Nizhnikovskii, and A. V. Fesenko, Russ J Electrochem, 42(3), 259 (2006).

59. M. Doyle, J. Electrochem. Soc, 143(6), 1890 (1996).

60. A. Funabiki, M. Inaba, Ogumi Zempachi, S.-I. Yuasa, J. Otsuji, and A. Tasaka, $J$ Electrochem. Soc., 172 (1998).

61. S. S. Zhang, K. Xu, and T. R. Jow, Electrochim. Acta, 48(3), 241 (2002).

62. M. D. Levi and D. Aurbach, J. Phys. Chem. B, 101(23), 4641 (1997).

63. D. Aurbach, J. Electrochem. Soc., 145(9), 3024 (1998).

64. S. T. Taleghani, B. Marcos, K. Zaghib, and G. Lantagne, J. Electrochem. Soc., 164(11), E3179 (2017)

65. S. V. Erhard, P. J. Osswald, J. Wilhelm, A. Rheinfeld, S. Kosch, and A. Jossen, J. Electrochem. Soc., 162(14), A2707 (2015).

66. B. J. McBride, M. J. Zehe, and S. Gordon, NASA Glenn Coefficients for Calculating Thermodynamic Properties of Individual Species, Ohio, USA (2002).

67. P. Arora and Z. Zhang, Chem. Rev., 104(10), 4419 (2004).

68. K. Kwon, F. Kong, F. McLarnon, and J. W. Evans, J. Electrochem. Soc., 150(2), A229 (2003).

69. D. R. Lide, Editor, CRC Handbook of Chemistry and Physics, Boca Raton, Florida, USA, CRC press (2006).

70. W. M. Haynes, D. R. Lide, and T. J. Bruno, CRC Handbook of Chemistry and Physics: A Ready-Reference Book of Chemical and Physical Data: 2013-2014, Boca Raton (Fla.), London, New York, CRC press (2013).

71. C.-D. Wen and I. Mudawar, International Journal of Heat and Mass Transfer, 47(1718), 3591 (2004) 